\title{
Osteological Atlas of Melanophryniscus (Anura, Bufonidae): A Synthesis after 150 Years of Skeletal Studies in the Genus
}

\author{
Facundo Deforel ${ }^{1}$, Ana Sofía Duport-Bru ${ }^{1}$, Sergio Daniel Rosset ${ }^{2}$, Diego Baldo ${ }^{3,4}$, and Florencia Vera Candioti ${ }^{1,4}$ \\ ${ }^{1}$ Unidad Ejecutora Lillo (CONICET - FML), 4000 San Miguel de Tucumán, Argentina \\ ${ }^{2}$ Sección Herpetología, División Zoología Vertebrados, Facultad de Ciencias Naturales y Museo, Universidad Nacional de La Plata, 1900 La Plata, \\ Argentina \\ ${ }^{3}$ Laboratorio de Genética Evolutiva "Claudio Juan Bidau," Instituto de Biología Subtropical (CONICET - UNaM), Facultad de Ciencias Exactas, \\ Universidad Nacional de Misiones, 3300 Posadas, Argentina
}

\begin{abstract}
Toads of the genus Melanophryniscus are known since the mid-late 19th Century, and the first skeletal description was made early in 1875 . However, it was not until the 1970s that osteological variation was discussed in a more inclusive taxonomic scenario. Derived from this, the first morphological synapomorphies proposed for the genus represented skeletal traits extracted from the few species considered in those studies. In this work, we examined the skeletons of 25 of the 29 currently recognized species of Melanophryniscus, plus three species under description, to examine their osteological variation and discuss the validity of those synapomorphic characters proposed, not only by analyzing their distribution within the genus but also by comparing them with the skeletal data available in the bibliography for other early branching bufonids. Our results show that main variations within the genus are related to changes in absolute body size and some proportions of postcranial elements. Except for M. setiba, an early diverging species that exhibits a number of autapomorphies, most skeletal traits are quite conserved throughout the genus. Members of the Melanophryniscus tumifrons group are distinctive by their nasal region, which tends to be taller than in other species, dome-shaped, and strongly exostosed. Most features considered diagnostic of the genus occur in other early branching bufonids, and are highly polymorphic, and this challenges earlier discussions on putative synapomorphies. For instance, exostosed frontoparietals only occur in M. setiba and M. klappenbachi, and the condition was also recorded for Osornophryne. The frontoparietal fontanelle, if present, may show different shapes and sizes (often similar to those in Osornophryne and some species of Atelopus). The zygomatic ramus of the squamosal may be absent or present as a small process, as described for some species of Atelopus, Osornophryne, and Truebella. Finally, posterolateral processes of the hyoid were observed in some early diverging species and hence we propose an alternative interpretation on its presence and distribution in the genus.
\end{abstract}

Key words: Axial skeleton; Cranium; Forelimbs; Hind limbs; Pectoral girdle; Pelvic girdle; Red-belly toads; Sesamoids; Synapomorphies

The genus Melanophryniscus Gallardo 1961 comprises 29 species of small to medium size bufonids commonly known as South American red-belly toads (Frost 2020). Distribution extends from the inter-Andean valleys of Bolivia to the Atlantic coast of southern Brazil, also covering Paraguay, Uruguay, and central and northern Argentina, and species can be found in biomes that cover open areas dominated by pastures (Uruguayan savannas), dry deciduous forests (Chaco and Cerrado), and rainforests (Atlantic Forest and Yungas; Caramaschi and Cruz 2002; Cruz and Caramaschi 2003; Peloso et al. 2012; Bornschein et al. 2015). These toads are one of the most conspicuous and distinctive Neotropical anurans because of their aposematic coloration patterns, the typically diurnal activity, lack of a tympanic middle ear, presence of complex advertisement calls, and explosive reproduction. The genus exhibits diverse reproductive modes that include oviposition and larval development in lotic environments, ponds, and also in small water volumes accumulated in plants (phytotelmata; Langone et al. 2008; Steinbach-Padilha 2008; Baldo et al. 2014; Bornschein et al. 2015). Within the genus, most species are traditionally assigned into three phenetic groups, Melanophryniscus moreirae, Melanophryniscus stelzneri, and Melanophryniscus tumifrons, based on coloration patterns and integumentary traits (Caramaschi and Cruz 2002; Fig. 1). Putative cytogenetic and morphological diagnostic traits were proposed for the M. tumifrons group (i.e., presence of a frontal skin gland and nucleolus organizer regions located on the

\footnotetext{
${ }^{4}$ Correspondence: e-mail, diegobaldo@gmail.com; florivc@gmail.com
}

fourth chromosome pair; Baldo and Basso 2004; Baldo et al. 2012a), but no clear diagnostic characters define the remaining intrageneric groups. Additionally, some described species are not assigned to any species group (e.g., DiBernardo et al. 2006; Langone et al. 2008).

Historically, the species of the genus Melanophryniscus have been included in at least five genera and six different families. Despite this complex taxonomic history, the genus was frequently found to be related to Atelopus, Dendrophryniscus (including Amazophrynella), and Oreophrynella in the former "Atelopodidae" (Miranda-Ribeiro 1920; Noble 1926; Ahl 1938). McDiarmid (1971) conducted an exhaustive review of these genera and proposed that they should be included within Bufonidae. Later, Cannatella (1986) and Graybeal and Cannatella (1995) described two new genera (Frostius and Truebella) and proposed relationships among "atelopodids," always considering it as a natural group. Subsequent studies using various sources of evidence, but mostly DNA sequences, showed that "Atelopodidae" is not a monophyletic group but includes independent lineages at the base of Bufonidae (Graybeal 1997; Darst and Cannatella 2004; Frost et al. 2006; Pramuk 2006; Roelants et al. 2007; Pramuk et al. 2008; Van Bocxlaer et al. 2010; Pyron 2014; Jetz and Pyron 2018). In all these analyses, Melanophryniscus was repeatedly recovered as the lineage that diverged earliest within the family. Although not rigorously tested, the monophyly of the genus has been suggested by many authors, based on morphological (McDiarmid 1971; Cannatella 1986; Larson et al. 2003), biochemical (e.g., presence of toxic lipophilic alkaloids acquired by the diet; Daly et al. 


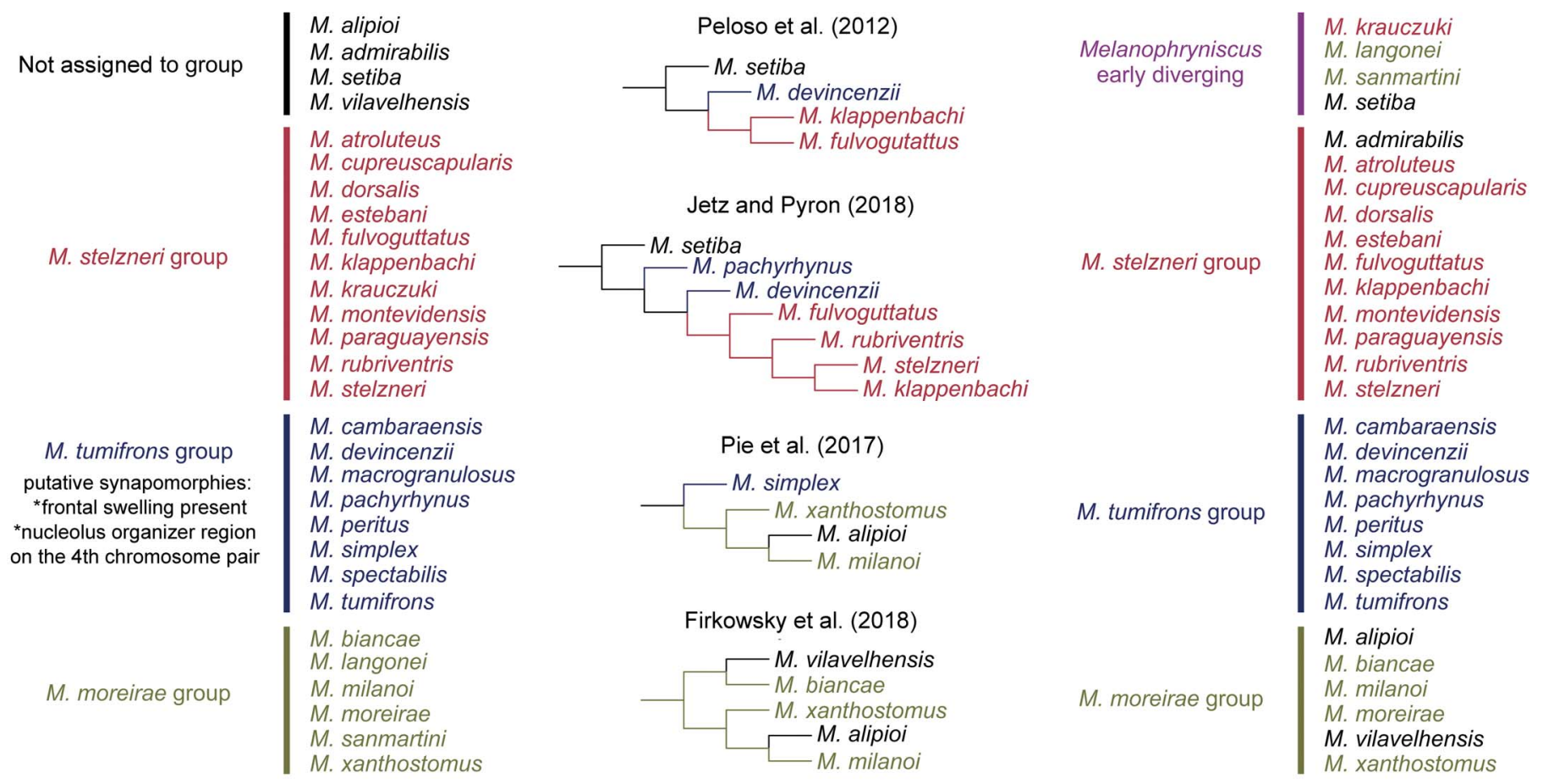

A

B C

FIG. 1.-Intrageneric arrangements of Melanophryniscus. (A) Phenetic groups as presented by Caramaschi and Cruz (2002) based on exomorphological features: M. stelzneri group, shallow warts with corneous spines, usually color pattern of contrasting dorsal spots or blotches, frontal swelling absent; $M$. tumifrons group, developed warts with apical corneus spine on dorsum and flanks, dorsum without contrasting color spots, frontal swelling present; $M$. moreirae group, developed warts with apical corneous spine on dorsum and flanks, dorsum without contrasting color spots, frontal swelling absent. Putative synapomorphies were proposed only for the M. tumifrons group. (B) Most-recent phylogenetic hypotheses proposed for subsets of species. (C) Arrangement used in this work based on Baldo (2012), Peloso et al. (2012), and Baldo et al. (2014). Note the changes in definition of intrageneric groups concerning mainly species of the M. moreirae and M. stelzneri groups. A color version of this figure is available online.

2008), and ethological characters (e.g., the unken-reflex defensive behavior; Toledo et al. 2011).

Osteological characters (e.g., maxillary teeth and girdle type) have been used since the mid-19th Century to place the species of Melanophryniscus taxonomically (Duméril and Bibron 1841; Günther 1858; Cope 1865; Noble 1922, 1926; Trewavas 1933; Badenhorst 1945; Vellard 1947; Griffiths 1954). The first complete osteological description of the genus was made by Jiménez de la Espada (1875) for $M$. montevidensis (as Phryniscus nigricans) and, subsequently, a few additional descriptions of skeletal anatomy were made mainly as part of taxonomic works ( $M$. rubriventris, McDiarmid 1972; M. krauczuki and M. atroluteus, Baldo and Basso 2004; M. paraguayensis, Céspedez and Motte 2007; M. estebani, Céspedez 2008; M. pachyrhynus, Baldo et al. 2012b; M. setiba, Peloso et al. 2012). Despite the scarce osteological knowledge, five traits are currently considered diagnostic for the genus; the configuration of frontoparietals, squamosals, orbitosphenoids, parasphenoids, and the hyoid apparatus (McDiarmid 1971; Cannatella 1986; Graybeal and Cannatella 1995).

Excepting the singular report of nasal ornamentation in the Melanophryniscus tumifrons group by Baldo et al. (2012b), no integrative, comparative work in skeletal morphology at a generic level has been attempted so far. Furthermore, observations often contradict the osteological diagnosis of the genus (e.g., configuration of frontoparietals; Peloso et al. 2012) or are conflictive due the lack of consensus on nomenclatural issues (e.g., definition of orbitosphenoid; Cannatella 1986). In this work, we compare the adult cranial and postcranial skeleton of Melanophryniscus species to provide a detailed osteological description for the genus and to discuss the osteological synapomorphies proposed for the clade. Our results provide a basis for discussing morphological evolution within early diverging bufonids.

\section{Materials and Methods}

We studied representatives of 25 out of 29 currently known species of Melanophryniscus, and we additionally examined specimens of three new species under description. Our assignment of species to intrageneric groups follows Baldo et al. (2014; Fig. 1). We consider four species not assigned to a group as early diverging lineages, following recent phylogenetic hypotheses (Baldo 2012; Peloso et al. 2012). Unfortunately, we could not include specimens of $M$. biancae, M. milanoi, M. peritus (each known only from the type series), and M. tumifrons (there are doubts about the origin of the holotype, which makes it challenging to assign specimens to this nominal species).

We studied a total of 94 adult specimens (1-13 per species). Some specimens were already dissected and information about sex and snout-vent length (SVL) was not available. In intact individuals, we assessed sexual maturity, recording the presence of mature gonads and secondary sexual characters (e.g., colored vocal sac and 
nuptial excrescences in males). We cleared specimens and double-stained them for bone and cartilage (Wassersug 1976), and observed and photographed skeletons with a Leica M205 stereomicroscope (Leica Microsystems). Osteological terminology follows McDiarmid (1971) and Trueb (1973), and we follow Grant et al. (2006) in their interpretation about palatine bones (neopalatines of Trueb 1993); nasal cartilage nomenclature follows Púgener and Maglia (2007); digits, carpal, and tarsal osteology follows Fabrezi (1992, 1993); hyolaryngeal apparatus description follows Trewavas (1933); and sesamoid identification was made according to Ponssa et al. (2010). Details of all specimens, including sex and SVL (when available) are summarized in the Appendix. For voucher material, we use the museum acronyms of Sabaj (2019).

We recorded cranial and postcranial standard measurements using the software Image J v1.52a (2018; National Institute of Health, Bethesda, MD). Measurements were based on those used in Guayasamin (2004) and Soliz et al. (2017), and we defined some new measurements to register variations in our sample. We took 72 osteological measurements (see Fig. 2). In the cranial skeleton, we registered the skull length (between the anteriormost part of the premaxillae and the posteriormost point of the tectum synoticum), skull maximum width (skull width at the level of suspensorium), antorbital width (skull width at the level of the antorbital margin), postorbital width (skull width at the level of the postorbital margin), condylar width (width between the occipital condyles), premaxilla length (between the anteriormost medial point of the pars dentalis and the posteriormost point of the posteromedial process), premaxilla width (at the frontal extension of the pars dentalis), maxilla length (between the anterolateral point of the pars dentalis and the free posterior tip), nasal length (between the narial opening and the tip of the maxillary process), pterygoid length (between the anteriormost point of the anterior ramus and the distal end of the posterior ramus), parasphenoid length (between the anteriormost point of the cultriform process and the posteriormost point of the posteromedial process), parasphenoid width (between the lateral tips of the alae), and parasphenoid angle (between the anterior tip of the cultriform process and the most distal point of the alae). In the axial skeleton we measured the column total length (between the anteriormost medial point of the Presacral Vertebra I and the tip of the urostyle), presacral region length (between the anteriormost medial point of the Presacral Vertebra I and the posteriormost medial tip of the condyle of Presacral Vertebra VIII), presacral vertebrae length (length of each vertebra, between its anteriormost point and the tip of the condyle), presacral vertebrae width (width of each vertebra, between the most lateral points of the cotyles - in Presacral Vertebra I-or the most lateral points of its transverse processes - in presacral vertebrae II-VIII), sacrum length (between its anteriormost point and the sacrum-urostyle joint), sacrum width (between the lateral extremes of sacral diapophyses), urostyle length, urostyle width (at the level of the anterior expansion), transverse process length (length of transverse process of vertebrae II-VIII, between the most lateral point and the region it joins the pedicle), sacral diapophysis length (between its most lateral medial point and the region it joins the pedicle), and transverse process/sacral diapophysis angle (between the most distal point of the process and the sagittal axis of the column). Girdle measurements include pectoral girdle width (between the medial head of the clavicle and the most distal point of the suprascapula), clavicle length (between its most medial point and the middle point of the acromial process), coracoid length (between its most medial point and the middle point of the fossa glenoidalis), clavicle-coracoid angle, scapula length (between its most distal point and the middle point of the acromial process), scapula width (between the anteriormost and posteriormost lateral points of the distal articular region), suprascapula length (between its most medial and distal points), sternum length (between the anteriormost part of the procoracoid and the posteriormost tip of the xiphisternum), pelvic girdle length (between the anterior tip of the iliac shaft and the posteriormost point of the ischium), supra-acetabular depression height (between the lowest point and the base of the pelvic girdle), supraacetabular expansion height (between the most dorsal point and the base of the pelvic girdle), iliac crest length, iliac protuberance height (between the most dorsal point of the iliac protuberance and the base of the pelvic girdle), and iliac shaft length (between its base and the anterior tip). Variations in limbs were registered taking the following measurements: humerus length (from the most proximal point of the glenoid epiphysis to the most distal point of the eminentia capitata), humeral ventral crest length (from its origin at the glenoid epiphysis and its distal end at the humeral diaphysis), radius length (between the midpoint of the proximal radial epiphysis and the most distal point of the radial condyle), ulna length (between the tip of the olecranon and the most distal point of the ulnar condyle), femur length (between the midpoint of the acetabular epiphysis and the most distal part of the distal condyles), tibiofibula length (along the sulcus intermedius), and tibialefibulare length (between the proximal and distal fibulare epiphyses).

In order to summarize patterns of morphometric variation in the genus, we performed principal component (PC) analyses on a reduced dataset of 49 linear measurements, excluding angles and 20 measurements that would be misleading in specimens with fused or supernumerary elements (column and presacral region lengths, parasphenoid length and width, sacrum length, and length, width, and transverse process length of presacral vertebrae VII and VIII) or were missing because of specimen damage (sternum length). Seven individuals had to be excluded for these reasons (see list in the Appendix). Although we did not explore the incidence of these exclusions, the resulting matrix still represents all studied species and major variations in cranial and postcranial anatomy. Two analyses were performed using the software Statistica v7.0 (2004; TIBCO Software Inc., Palo Alto, CA). A first analysis was made on raw measurements in order to analyze patterns of size variation in the genus. A second analysis was performed on a size-corrected dataset, using residuals from bivariate regressions of each measurement on a size estimate. Because SVLs were not available for all specimens, as commented above, we used the geometric mean of the 49 raw linear measurements, calculated as the 49th root of the product of 49 measurements. Principal components with higher variances were explored, and factor loadings (i.e., correlation 

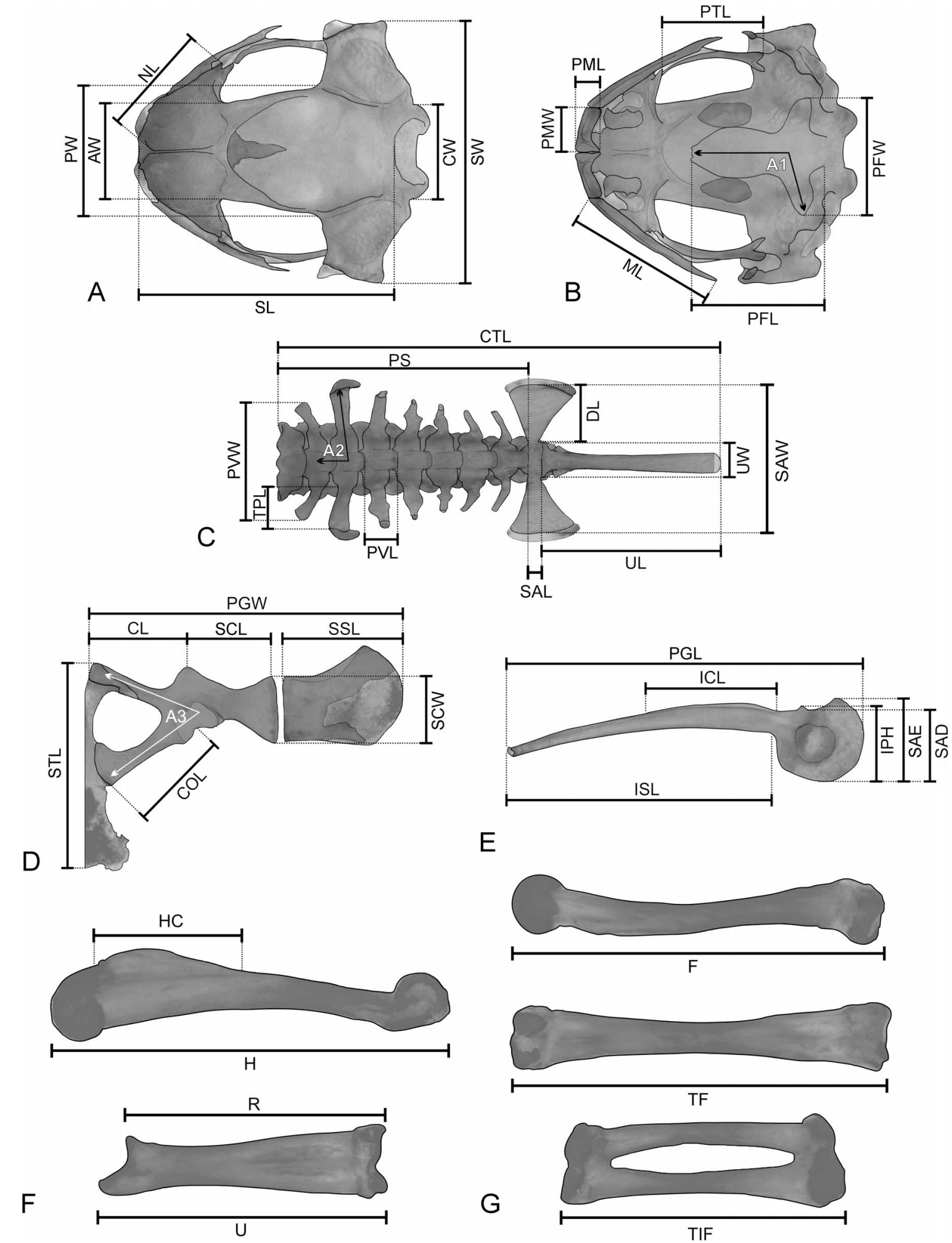

$\mathrm{E}$
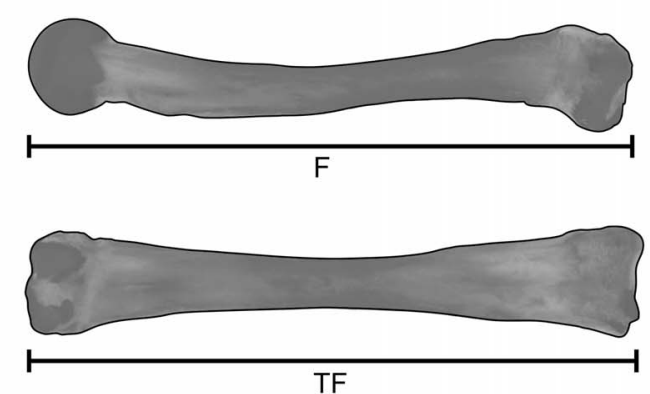

G

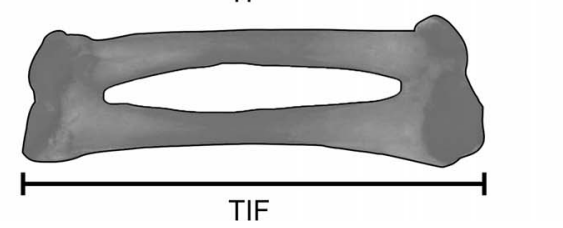

FIG. 2.-Cranial and postcranial measurements taken in specimens of Melanophryniscus. (A) Skull in dorsal view, (B) skull in ventral view, (C) axial skeleton, (D) pectoral girdle, (E) pelvic girdle, (F) forelimb excluding the autopodium, and (G) hind limb excluding the autopodium. A1 = parasphenoid angle, $\mathrm{A} 2=$ transverse process angle, $\mathrm{A} 3=$ clavicle-coracoid angle, $\mathrm{AW}=$ antorbital width, $\mathrm{CL}=$ clavicle length, $\mathrm{COL}=\mathrm{coracoid}$ length, $\mathrm{CTL}=\mathrm{column}$ total length, $\mathrm{CW}=$ condylar width, $\mathrm{DL}=$ sacral diapophysis length, $\mathrm{F}=$ femur length, $\mathrm{H}=$ humerus length, $\mathrm{HC}=$ humeral ventral crest length, ICL = iliac crest length, IPH = iliac protuberance height, ISL = iliac shaft length, ML = maxilla length, NL = nasal length, PFL = parasphenoid length, PFW = parasphenoid width, PGL = pelvic girdle length, PGW = pectoral girdle width, PML = premaxilla length, $\mathrm{PMW}=$ premaxilla width, $\mathrm{PS}=$ presacral region length, $\mathrm{PTL}=$ pterygoid length, $\mathrm{PVL}=$ presacral vertebrae length, $\mathrm{PVW}=$ presacral vertebrae width, $\mathrm{PW}=$ postorbital width, $\mathrm{R}=$ radius length, $\mathrm{SAD}=$ supra-acetabular depression height, $\mathrm{SAE}=$ supra-acetabular expansion height, $\mathrm{SAL}=$ sacrum length, $\mathrm{SAW}=$ sacrum width, $\mathrm{SCL}=$ scapula length, $\mathrm{SCW}=$ scapula width, SL = skull length, SSL = suprascapula length, STL = sternum length, SW = skull maximum width, TF = tibiofibula length, TIF $=$ tibialefibulare length, TPL $=$ transverse process length, $\mathrm{U}=$ ulna length, $\mathrm{UL}=$ urostyle length, $\mathrm{UW}=$ urostyle width. 
values between the original measurements and the PCs) were calculated.

\section{RESUlts}

The detailed osteological description is based on an adult male of Melanophryniscus spectabilis (LGE 22700), and intra- and interspecific variations are summarized in comparison, when pertinent. Raw measurements are given in the Supplemental Material, and Tables 1 and 2 show measurement ratios per species. Values in text summarize variation at a generic level and are given as range (mean \pm standard deviation $[\mathrm{SD}])$.

\section{Cranium}

The skull is almost quadrangular, slightly wider than long (skull length/skull maximum width $=0.82-1.02[0.93 \pm$ $0.05]$; Fig. 3), with the anterior region rounded. The maximum width is at the level of the posteriormost part of the crista parotica. Most skull elements are well ossified and fused to each other forming an akinetic unit. For organizational purposes in our description, we recognize a nasal region, sphenethmoid complex and orbitosphenoid, palatal region, braincase roof, otoccipital region, auditory apparatus, upper jaw (maxillary arcade), lower jaw, and suspensorium (Fig. 3A,B).

Nasal region.-In dorsal view nasals have a nearly triangular contour (Figs. 3A, 6). They are relatively large (nasal length/skull length $=0.35-0.49[0.41 \pm 0.03]$ ) and almost contiguous medially, leaving slight separations at the anterior and posterior ends. Bone maximum height is in the central portion (Fig. 3C). Nasals extend posterolaterally to form well-developed maxillary processes that descend to the internal face of the maxillae without contacting it. Nasals overlap the planum antorbitale posterolaterally and cover the sphenethmoid complex posteromedially; in some specimens, nasals can be slightly occluded by the anterior margin of the frontoparietals (e.g., M. dorsalis, M. montevidensis, and some specimens of M. spectabilis). Across species, nasals vary widely in height and ornamentation. Higher nasals are observed in M. estebani, M. klappenbachi, M. rubriventris, and M. stelzneri, and relatively lower nasals are characteristic of M. alipioi, M. langonei, and M. setiba.

Species of the Melanophryniscus tumifrons group have slightly rounded nasals that may undergo a deep exostosis, rendering the dorsal surface commonly striated or rugose (Figs. 3A, 4A, 5C). Markedly dome-shaped and strongly exostosed nasals were observed in M. devincenzii (Fig. 5C) and $M$. aff. devincenzii and to a lesser degree in $M$. macrogranulosus and $M$. pachyrhynus. In contrast, $M$. cambaraensis specimens show comparatively shorter and smoother nasals. Outside the M. tumifrons group, M. setiba is the only species with exostosed nasals.

The olfactory capsules (Fig. 4) are sagittally separated by a slender septum nasi fused to the nasals. The roof of the capsules is composed by the tectum nasi that is integrated, at least at its posteriormost region, to the dorsal surface of the nasals. The solum nasi constitutes the floor of the capsule and is integrated with the palatal bones and the sphenethmoid. The septum nasi, solum nasi, and at least the posteriormost part of the tectum nasi are ossified. Internal and rostral cartilaginous elements are often barely visible
(Figs. 4B, 5). Oblique cartilages form dome-like structures encircling the external narial openings. Each cartilage curves downward and is continuous with the planum terminale, which in turn connects posteriorly with the anteriormost part of the slender paranasal commissure. The cartilaginous planum antorbitale remains visible as a small surface restricted laterally (Melanophryniscus klappenbachi and some specimens of M. stelzneri and M. aff. devincenzii) or as a strip that occupies half of the antorbital edge of the palate floor (M. alipioi, M. langonei, and one specimen of $M$. sanmartini). At its distal end this cartilage projects forward to form the anterior maxillary process. The posterior maxillary process fuses to the rostral end of the pterygoid cartilage at the level of the maxilla-pterygoid articulation. Rostral and ventrally, alary and inferior prenasal cartilages, and the crista subnasalis are distinct. The distal edge of the crista subnasalis reaches the level of the maxilla-premaxilla joint and abuts the internal surface of the pars facialis of the maxilla through a pair of delicate anterior and posterior rami. The septomaxillae remain embedded within the external narial region of each olfactory capsule, ventrally to the anterior margin of the nasals and above the maxillapremaxilla articulation point (Fig. 4A). Septomaxillae are U-shaped and show two stout processes.

Sphenethmoid complex and orbitosphenoid.--The sphenethmoid complex (sensu McDiarmid 1971) refers to the anterior portion of the neurocranium, including the fusion of the sphenethmoid with the endochondral nasal structures (Fig. 3C, 4A). It is partially covered by the frontoparietals and nasals dorsally and by the palatines, vomers, and the cultriform process of the parasphenoid ventrally. It is integrated with the investing dermal bones in various ways, but commonly fused with the rostral margin of the cultriform process of the parasphenoid (see below). The sphenethmoid complex forms the anterior wall of the orbits and laterally joins the inner face of the maxillae through the cartilaginous lateral region of the planum antorbitale. The region surrounding the optic foramen, referred as to orbitosphenoid by McDiarmid (1971), is fully ossified in most specimens, and in general is indistinguishable from the sphenethmoid and prootics (Fig. 3C). In some specimens, a slender cartilaginous stripe (M. langonei, M. krauczuki, and some specimens of $M$. montevidensis and M. rubriventris) or soft tissue (one specimen of $M$. sanmartini and $M$. spectabilis) remains at the skull floor at the level of the optic foramina. Single specimens of M. cupreuscapularis, M. krauczuki, and M. rubriventris have a slight ornamentation of the ventral surface of the sphenethmoid.

Palatal region.- The palatal region is composed by three bones, i.e., vomers, palatines, and the parasphenoid (Fig. 3B). The paired vomers underlie the floor of the olfactory capsules at the anterolateral quarters of the solum nasi region. They are widely separated medially, and their anteroposterior axes are aligned with the neurocranium axis. Each vomer bears a narrowed anterior process, and reduced prechoanal and postchoanal processes that form the medial margins of the choana. Dentigerous processes are absent.

When discernible, the palatines are slender, slightly curved, and laterally expanded bones that rest in the ventral surface of the planum antorbitale at the anteroventral margin of the orbit. They never reach the pars facialis of the maxillae. Palatines usually appear as barely distinguishable 


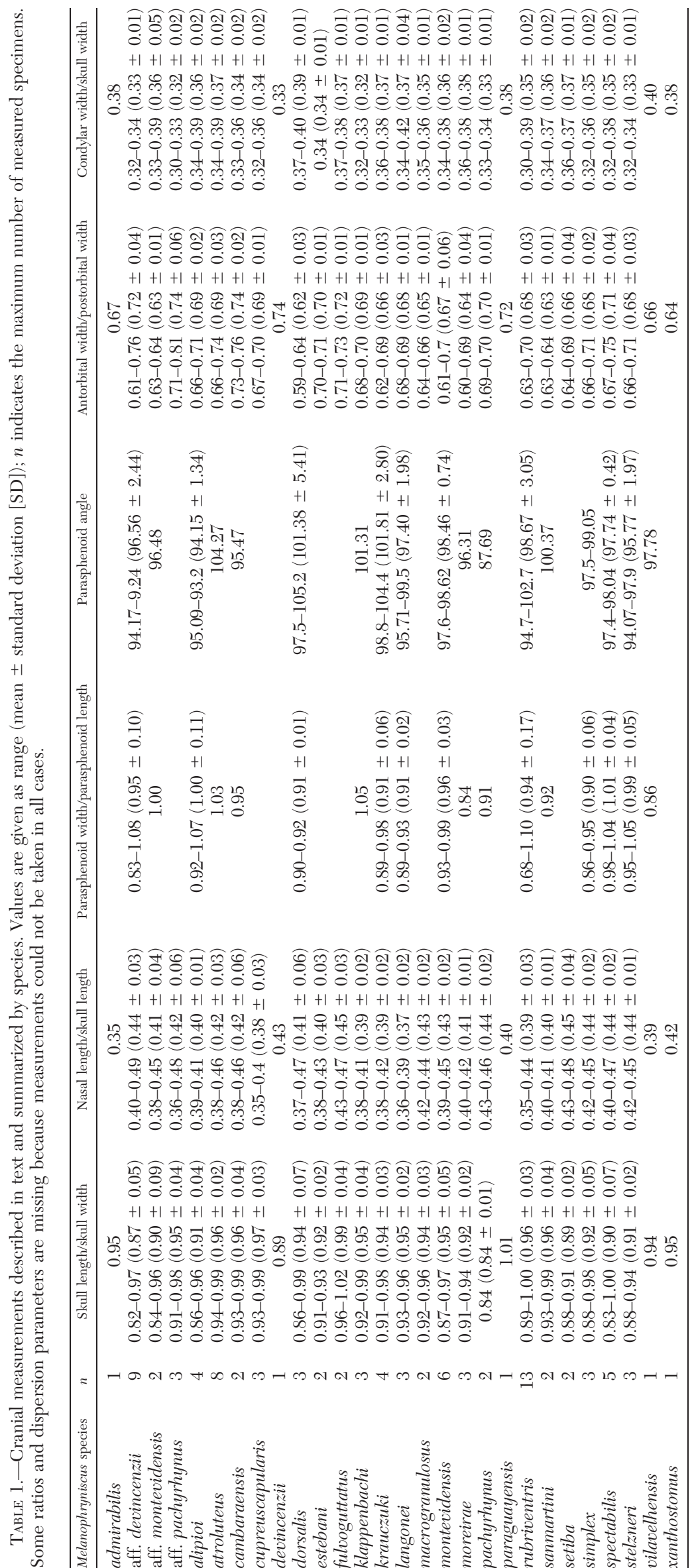




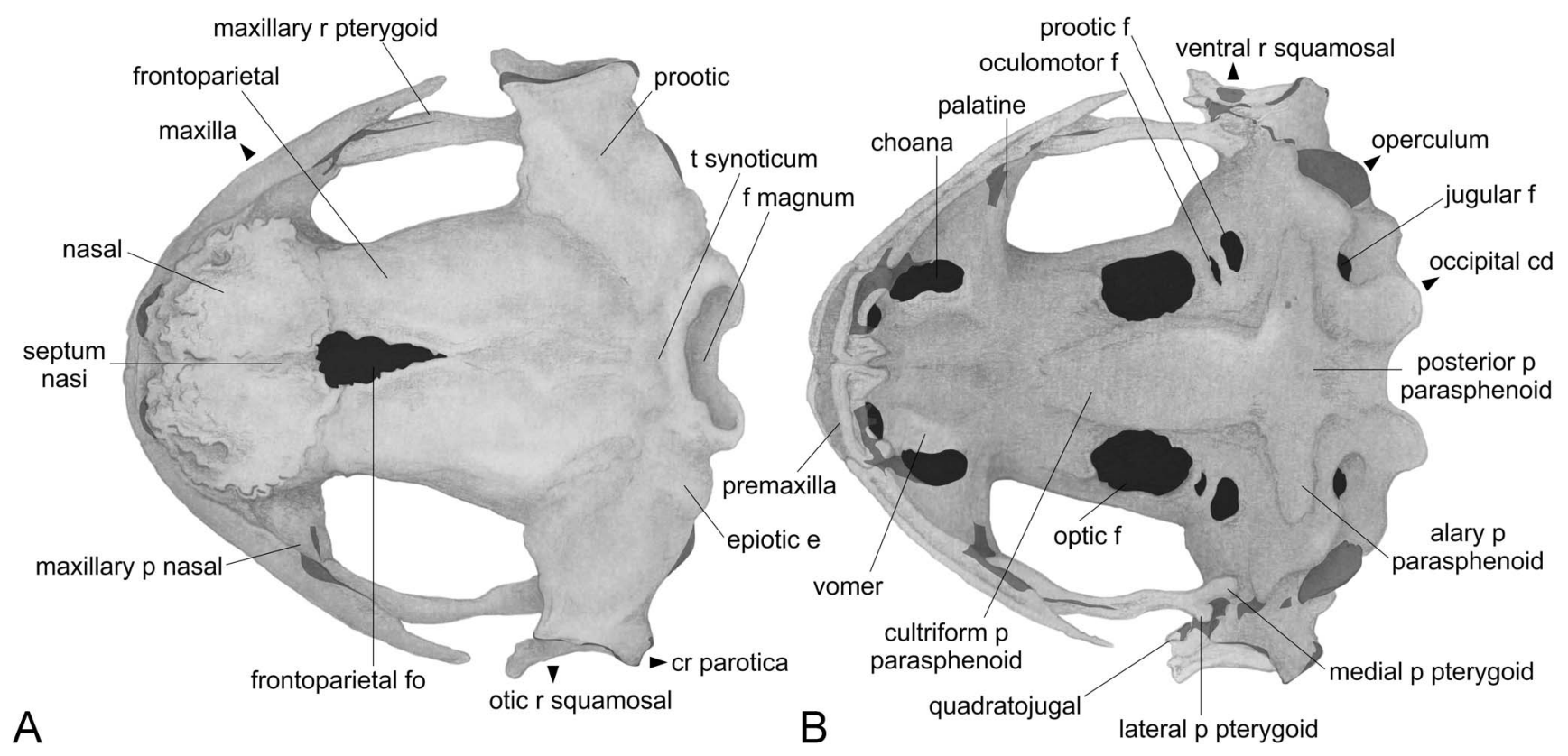

A

B
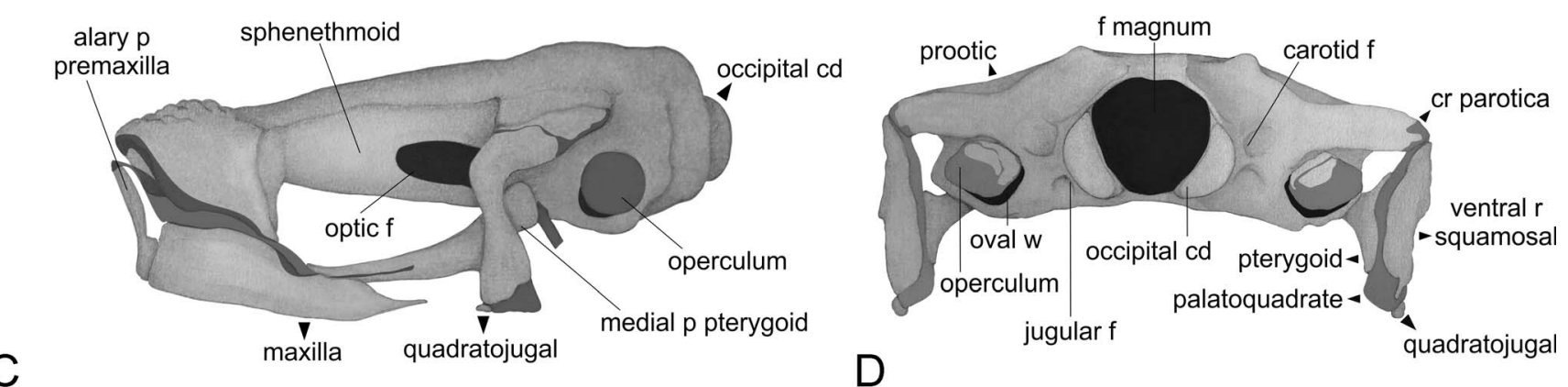

FIG. 3.-Skull of Melanophryniscus spectabilis (LGE 22700) in (A) dorsal, (B) ventral, (C) lateral, and (D) posterior views. Cartilage (solid grey), bone ( haded grey), and foramina or fenestrae (black). $\mathrm{cd}=$ condyle, $\mathrm{cr}=$ crista, $\mathrm{e}=$ eminence, $\mathrm{f}=$ foramen, fo $=$ fontanelle, $\mathrm{p}=\mathrm{process}, \mathrm{r}=\mathrm{ramus}, \mathrm{t}=$ tectum, $\mathrm{w}=$ window. Scale bar $=1 \mathrm{~mm}$

bony ridges in specimens of most of the species, as suggested by more strongly stained areas where these bones are located. However, in some individuals of Melanophryniscus alipioi, M. atroluteus, M. klappenbachi, M. paraguayensis, M. rubriventris, M. setiba, and M. stelzneri, palatines are hardly recognizable. In one young specimen of $M$. aff. devincenzii and one specimen of M. montevidensis, a pair of slender palatines are visible as discrete elements.

The parasphenoid has a T-shaped aspect, with distinct cultriform process and lateral alae, plus a caudal posteromedial process. When discernible as a discrete element-not fused to the neurocranium throughout all its edges-the parasphenoid tends to be slightly longer than wide (parasphenoid width/parasphenoid length $=0.68-1.10[0.98 \pm$ $0.08]$ ). The cultriform process does not reach the palatines and its lateral margins are convex, wider at its midpoint, and progressively narrowing anteriorly. Its anterior margin is irregular and dentate. The parasphenoid alae project posterolaterally from the longitudinal axis at an angle slightly larger than $90^{\circ}$ (parasphenoid angle $=87.69-105.20[97.91$ $\pm 3.40]$ ), without reaching the level of the pterygoid. The posteromedial process is short and wide and commonly fused to underlying exoccipitals. The parasphenoid is observed as a completely discrete element only in some specimens of $M$. aff. devincenzii, $M$. aff. montevidensis, $M$. dorsalis, and M. montevidensis, while in some individuals only the cultriform process and lateral alae are free from the ventral surface of the neurocranium (M. aff. devincenzii, $M$. alipioi, M. krauczuki, M. langonei, M. montevidensis, M. moreirae, M. rubriventris, M. sanmartini, M. simplex, M. spectabilis, M. stelzneri, and M. vilavelhensis). A partially fused parasphenoid - with free cultriform processes-is present in some individuals of M. estebani, M. montevidensis, M. rubriventris, M. sanmartini, M. simplex, and $M$. spectabilis. Finally, a parasphenoid strongly fused to the neurocranium is present in $M$. cupreuscapularis, $M$. fulvoguttatus, M. klappenbachi, M. paraguayensis, M. setiba, M. xanthostomus, and some individuals of $M$. aff. devincenzii, M. alipioi, M. atroluteus, M. estebani, and M. stelzneri. The parasphenoid of single specimens of M. cupreuscapularis and M. rubriventris shows slight ornamentation in some areas.

Braincase roof.-The paired frontoparietals roof the braincase and constitute the mid dorsal wall of the orbits (Figs. 3A, 6). In dorsal view, frontoparietals together adopt an almost hexagonal shape, with its maximum width on the 
TABLE 2.-Postcranial measurements described in text and summarized by species. Values are given as range (mean \pm standard deviation [SD]); $n$ indicates the maximum number of measured specimens. Some ratios and dispersion parameters are missing because measurements could not be taken in all cases.

\begin{tabular}{|c|c|c|c|c|c|}
\hline Melanophryniscus species & $n$ & $\begin{array}{l}\text { Urostyle length/ } \\
\text { column length }\end{array}$ & $\begin{array}{c}\text { Sternum length/ } \\
\text { pectoral girdle width }\end{array}$ & $\begin{array}{l}\text { Iliac shaft length/ } \\
\text { pelvic girdle width }\end{array}$ & $\begin{array}{l}\text { Iliac crest length/ } \\
\text { iliac shaft length }\end{array}$ \\
\hline aff. devincenzii & 9 & $0.32-0.46(0.42 \pm 0.04)$ & $0.59-0.70(0.64 \pm 0.04)$ & $0.69-0.71(0.70 \pm 0.01)$ & $0.54-0.65(0.60 \pm 0.04)$ \\
\hline aff. montevidensis & 2 & 0.37 & $0.49-0.56(0.52 \pm 0.05)$ & $0.68-0.72(0.70 \pm 0.03)$ & $0.51-0.55(0.53 \pm 0.03)$ \\
\hline alipioi & 4 & $0.39-0.40(0.40 \pm 0.01)$ & $0.57-0.66(0.61 \pm 0.05)$ & $0.67-0.70(0.68 \pm 0.01)$ & $0.51-0.66(0.57 \pm 0.06)$ \\
\hline atroluteus & 8 & $0.36-0.40(0.38 \pm 0.01)$ & $0.53-0.59(0.56 \pm 0.02)$ & $0.67-0.70(0.69 \pm 0.01)$ & $0.49-0.61(0.54 \pm 0.04)$ \\
\hline cambaraensis & 2 & $0.38-0.41(0.39 \pm 0.02)$ & $0.73(0.73 \pm 0.01)$ & $0.67-0.68(0.68 \pm 0.01)$ & $0.54-0.70(0.62 \pm 0.12)$ \\
\hline estebani & 2 & 0.39 & 0.53 & $0.69-0.70(0.70 \pm 0.01)$ & $0.54-0.60(0.57 \pm 0.04)$ \\
\hline fulvoguttatus & 2 & $0.40-0.41(0.41 \pm 0.01)$ & 0.55 & $0.64-0.65(0.65 \pm 0.01)$ & $0.66-0.74(0.70 \pm 0.05)$ \\
\hline klappenbachi & 3 & $0.38-0.41(0.39 \pm 0.01)$ & $0.51-0.57(0.55 \pm 0.03)$ & $0.69-0.70(0.69 \pm 0.01)$ & $0.53-0.61(0.58 \pm 0.05)$ \\
\hline krauczuki & 4 & $0.37-0.40(0.39 \pm 0.02)$ & $0.52-0.58(0.54 \pm 0.03)$ & $0.69-0.71(0.70 \pm 0.01)$ & $0.55-0.71(0.61 \pm 0.08)$ \\
\hline langonei & 3 & $0.31-0.33(0.32 \pm 0.01)$ & $0.61-0.65(0.63 \pm 0.03)$ & $0.68-0.70(0.69 \pm 0.01)$ & $0.51-0.60(0.56 \pm 0.05)$ \\
\hline macrogranulosus & 2 & $0.29-0.42(0.35 \pm 0.09)$ & 0.79 & $0.67-0.69(0.68 \pm 0.01)$ & $0.56-0.64(0.60 \pm 0.05)$ \\
\hline sanmartini & 2 & 0.42 & $0.70-0.71(0.71 \pm 0.01)$ & $0.69-0.72(0.71 \pm 0.02)$ & $0.64(0.64 \pm 0.01)$ \\
\hline setiba & 2 & $0.40-0.45(0.43 \pm 0.04)$ & $0.59-0.60(0.60 \pm 0.01)$ & $0.69-0.73(0.71 \pm 0.02)$ & $0.55-0.57(0.56 \pm 0.01)$ \\
\hline simplex & 3 & $0.38-0.43(0.41 \pm 0.03)$ & $0.55-0.65(0.61 \pm 0.05)$ & $0.70-0.78(0.73 \pm 0.04)$ & $0.53-0.60(0.56 \pm 0.04)$ \\
\hline spectabilis & 5 & $0.34-0.48(0.43 \pm 0.05)$ & $0.56-0.66(0.60 \pm 0.05)$ & $0.69-0.75(0.71 \pm 0.02)$ & $0.48-0.58(0.53 \pm 0.04)$ \\
\hline stelzneri & 3 & $0.36-0.37(0.37 \pm 0.01)$ & $0.54-0.57(0.55 \pm 0.02)$ & $0.65-0.67(0.66 \pm 0.01)$ & $0.53-0.62(0.56 \pm 0.05)$ \\
\hline vilavelhensis & 1 & 0.40 & 0.51 & 0.67 & 0.57 \\
\hline xanthostomus & 1 & 0.42 & 0.61 & 0.70 & 0.58 \\
\hline
\end{tabular}

postorbital region (antorbital width/postorbital width $=$ $0.59-0.81[0.68 \pm 0.04])$. They overlap the sphenethmoid complex anteriorly and the otoccipital region posteriorly, but never reach the foramen magnum. Frontoparietals remain separate along their whole extent or articulate to each other posteriorly (e.g., Melanophryniscus simplex); both states are observed in M. rubriventris and M. montevidensis (Fig. $6 \mathrm{~A}, \mathrm{~B})$. Posterior fusion may occur to different degrees. The anterior divergence of frontoparietals results in a V-shaped frontoparietal fontanelle in most species (e.g., M. cambaraensis; Fig. 6C), though it may become a wide, U-shaped gap in M. sanmartini, M. estebani, M. langonei, and M. vilavelhensis (Fig. 6D,E). Specimens of M. krauczuki exhibit both V-and U-shaped fontanelles. In contrast, frontoparietals are fused all along the midline in $M$. fulvoguttatus, $M$. klappenbachi, and M. setiba (Fig. 6F,G), or almost fully fused, sometimes involving its anterior margin and leaving only a small opening in its anteriormost portion in some specimens of M. atroluteus, M. cupreuscapularis, and $M$. aff. devincenzii (Fig. 6H). Exostosed frontoparietals are found in $M$. setiba and a single specimen of M. klappenbachi (Fig. $6 \mathrm{~F}, \mathrm{G})$.

Otoccipital region.-This region is composed by the exoccipitals and the prootics integrated into a single structure at the posterior portion of the skull (Fig. 3). Prootics form most of the otic capsules and are elevated at their dorsomedial region, forming a relatively high epiotic eminence, which may be partially overlapped by the posterolateral margins of the frontoparietals. The crista parotica represents the lateral edges of prootics, where the otic ramus of the squamosal abuts. It is at least partially cartilaginous in most species, except for $M$. devincenzii, M. setiba, and some specimens of $M$. aff. devincenzii, $M$. klappenbachi, and M. pachyrhynus. A prootic foramen opens ventrally approximately at the level of the medial ramus of pterygoid. The oculomotor foramen is smaller and located anteromedially with respect to the prootic foramen. Dorsal surface of prootics may present some sculpturing, more evident in $M$. cambaraensis, $M$. devincenzii, $M$. macrogranulosus, M. setiba, some specimens of $M$. aff. devincenzii, M. klappenbachi, M. krauczuki, and one specimen of M. estebani (Fig. 6). The ventral surface of prootics is slightly sculptured in single specimens of $M$. cupreuscapularis, M. krauczuki, and M. rubriventris.

Exoccipitals form the posteromedial walls of the otic capsules, the margins of the foramen magnum, and the occipital condyles. They are fused to each other medially and laterally with the prootics, anteriorly with the frontoparietals, and articulate with the cotylar facets of the first presacral vertebra posteriorly. In some specimens of Melanophryniscus alipioi, M. atroluteus, and M. spectabilis, a less stained and barely distinguishable triangular region at the exoccipital dorsomedial surface may correspond to the tectum synoticum. On ventral view, each exoccipital extends laterally, reaching the level of the medial ramus of the pterygoid, partially overlapped by the alae of the parasphenoid. Two pairs of foramina open at the posterior wall of the otoccipital region, lateral to the occipital condyles, and both approximately at the level of the posterior rami of the epiotic eminence: the jugular foramina occur in a more ventral position and the carotid foramina are slightly dorsal (Fig. 3D). The occipital condyles are widely separated and have rounded articular surfaces (condylar width/skull maximum width $=0.30-0.42[0.35 \pm 0.02])$. The foramen magnum is 


\begin{tabular}{|c|c|c|c|}
\hline $\begin{array}{l}\text { Humeral crest length/ } \\
\text { humerus length }\end{array}$ & $\begin{array}{l}\text { Radius length/ } \\
\text { ulna length }\end{array}$ & $\begin{array}{l}\text { Tibiofibula length/ } \\
\text { femur length }\end{array}$ & $\begin{array}{l}\text { Tibiale-fibulare length/ } \\
\text { tibiofibula length }\end{array}$ \\
\hline 0.48 & 0.81 & 0.99 & 0.68 \\
\hline $0.34-0.44(0.39 \pm 0.04)$ & $0.88-0.93(0.90 \pm 0.01)$ & $0.98-1.04(1.00 \pm 0.02)$ & $0.59-0.69(0.65 \pm 0.03)$ \\
\hline $0.35-0.37(0.36 \pm 0.01)$ & $0.88(0.88 \pm 0.01)$ & $0.94-1.00(0.97 \pm 0.04)$ & $0.63-0.68(0.66 \pm 0.03)$ \\
\hline $0.50-0.56(0.53 \pm 0.03)$ & $0.88-0.89(0.88 \pm 0.01)$ & $0.98-1.01(1.00 \pm 0.02)$ & $0.65-0.70(0.67 \pm 0.02)$ \\
\hline $0.34-0.41(0.38 \pm 0.04)$ & $0.87-0.90(0.89 \pm 0.01)$ & $0.89-1.01(0.95 \pm 0.05)$ & $0.63-0.69(0.66 \pm 0.02)$ \\
\hline $0.34-0.56(0.41 \pm 0.07)$ & $0.86-0.92(0.88 \pm 0.02)$ & $0.94-1.01(0.97 \pm 0.04)$ & $0.60-0.76(0.65 \pm 0.05)$ \\
\hline $0.38-0.40(0.39 \pm 0.01)$ & $0.80-0.86(0.83 \pm 0.04)$ & $0.99-1.03(1.01 \pm 0.02)$ & $0.62-0.67(0.64 \pm 0.04)$ \\
\hline $0.41-0.43(0.43 \pm 0.01)$ & $0.86-0.89(0.87 \pm 0.02)$ & $0.99-1.04(1.01 \pm 0.03)$ & $0.65-0.67(0.66 \pm 0.01)$ \\
\hline 0.40 & 0.94 & 0.90 & 0.69 \\
\hline $0.36(0.36 \pm 0.01)$ & $0.88-0.92(0.90 \pm 0.02)$ & $0.97-1.15(1.06 \pm 0.09)$ & $0.62-0.69(0.65 \pm 0.03)$ \\
\hline $0.41-0.42(0.41 \pm 0.01)$ & $0.85-0.87(0.86 \pm 0.01)$ & $0.95-1.03(0.99 \pm 0.06)$ & $0.66-0.68(0.67 \pm 0.01)$ \\
\hline $0.38-0.40(0.39 \pm 0.01)$ & $0.89-0.93(0.91 \pm 0.03)$ & $0.97-1.02(0.99 \pm 0.04)$ & $0.64-0.65(0.65 \pm 0.01)$ \\
\hline $0.39-0.42(0.41 \pm 0.02)$ & $0.86-0.93(0.89 \pm 0.03)$ & $0.92-1.00(0.97 \pm 0.05)$ & $0.61-0.70(0.66 \pm 0.04)$ \\
\hline $0.34-0.44(0.40 \pm 0.05)$ & $0.88-0.90(0.89 \pm 0.01)$ & $0.91-0.98(0.94 \pm 0.04)$ & $0.67-0.72(0.69 \pm 0.02)$ \\
\hline $0.41-0.45(0.43 \pm 0.02)$ & $0.87-0.89(0.88 \pm 0.01)$ & $1.03-1.05(1.05 \pm 0.01)$ & $0.59-0.69(0.64 \pm 0.05)$ \\
\hline $0.34(0.34 \pm 0.01)$ & $0.89(0.89 \pm 0.01)$ & $1.05-1.06(1.05 \pm 0.01)$ & $0.63(0.63 \pm 0.01)$ \\
\hline $0.32-0.53(0.42 \pm 0.09)$ & $0.84-0.89(0.87 \pm 0.02)$ & $0.99-1.11(1.05 \pm 0.05)$ & $0.55-0.73(0.64 \pm 0.06)$ \\
\hline $0.38-0.44(0.41 \pm 0.03)$ & $0.85-0.89(0.88 \pm 0.02)$ & $0.96-1.03(0.99 \pm 0.03)$ & $0.67-0.68(0.68 \pm 0.01)$ \\
\hline $0.29-0.41(0.35 \pm 0.08)$ & $0.88(0.88 \pm 0.01)$ & $0.99(0.99 \pm 0.01)$ & $0.66-0.69(0.67 \pm 0.02)$ \\
\hline 0.42 & 0.87 & 0.95 & 0.64 \\
\hline $0.40-053(0.47 \pm 0.04)$ & $0.86-0.90(0.88 \pm 0.01)$ & $0.94-1.03(0.99 \pm 0.03)$ & $0.61-0.67(0.64 \pm 0.02)$ \\
\hline $0.40-0.42(0.41 \pm 0.01)$ & $0.87(0.87 \pm 0.01)$ & $0.98-1.03(1.01 \pm 0.03)$ & $0.63-0.66(0.64 \pm 0.02)$ \\
\hline $0.31-0.37(0.34 \pm 0.04)$ & $0.88-0.89(0.88 \pm 0.01)$ & $0.96-0.98(0.97 \pm 0.01)$ & $0.72-0.73(0.73 \pm 0.01)$ \\
\hline $0.43-0.48(0.45 \pm 0.03)$ & $0.87-0.91(0.88 \pm 0.02)$ & $0.99-1.00(1.00 \pm 0.01)$ & $0.64-0.66(0.66 \pm 0.01)$ \\
\hline $0.31-0.46(0.41 \pm 0.06)$ & $0.87-0.91(0.89 \pm 0.02)$ & $0.98-1.02(1.00 \pm 0.02)$ & $0.64-0.68(0.66 \pm 0.01)$ \\
\hline $0.39-0.44(0.42 \pm 0.03)$ & $0.86-0.93(0.88 \pm 0.04)$ & $0.97-1.02(1.00 \pm 0.02)$ & $0.60-0.68(0.65 \pm 0.04)$ \\
\hline 0.51 & 0.88 & 0.98 & 0.63 \\
\hline 0.45 & 0.88 & 0.97 & 0.71 \\
\hline
\end{tabular}

wide, with a concave dorsal margin and a straight to slightly curved ventral margin. A slight ornamentation of the ventral and posterior surfaces of exoccipitals occurs in single specimens of M. cupreuscapularis and M. rubriventris.

Auditory apparatus. - Opercula are wide, convex, and nearly rounded cartilaginous structures located on the posteroventral wall of the otic capsules. They mineralize to varying degrees, completely in some specimens of Melanophryniscus aff. devincenzii, M. pachyrhynus, and $M$. spectabilis, or almost completely in $M$. devincenzii, $M$. klappenbachi, and some specimens of $M$. montevidensis, $M$. moreirae, and M. rubriventris. Each operculum closes the oval window almost entirely, leaving a small slit on its ventral margin. Tympanic middle ear is absent.

Upper jaw.-The edentate premaxillae form the anteriormost segments of each maxillary arch and are in close contact with each other and with the pars palatina of the adjacent maxillae (Figs. 3B, 4). The three usual portions are clearly discernible. The alary process is inclined forward in profile (Fig. 5). The anterior margin of the pars dentalis is slightly convex. Both alary process and pars dentalis are wider and have a more robust aspect in Melanophryniscus admirabilis, M. aff. devincenzii, M. aff. pachyrhynus, M. cambaraensis, and M. devincenzii; in M. alipioi, M. langonei, and in some individuals of $M$. spectabilis and M. stelzneri, they are considerably slender. A markedly shorter alary process is characteristic of M. setiba. The pars palatina is well developed, concave, and bears a well-developed triangular posteromedial process and a deeply reduced posterolateral process. On its longest region, at the level of the posteromedial process, the pars palatina reaches about half the width of premaxilla.
The maxillae are the largest bony elements of the maxillary arcade (Fig. 5). Each maxilla is elongated and slightly curved and bears a distinct pars dentalis visible as a thin ridge on its ventrolateral surface, a broader pars palatina, and a slightly curved-upwards pars facialis. The anterior tip of the pars facialis is blunt. In ventral view, each maxilla narrows progressively from the surface of articulation with the anterior ramus of the pterygoid to its posterior end. It never reaches the quadratojugal. The pars facialis is well developed, reaching its maximum height at the level of the nasals, from the posterior margin of the planum antorbitale up to its anterior tip. The nasal process is indistinguishable. A wide surface of the inner face of the pars facialis articulates to the anterolateral region of the maxillary ramus of the pterygoid through the pterygoid cartilage. It also contacts the maxillary process of the planum antorbitale cartilage. The pars palatina is uniformly wide from the maxilla-pterygoid articulation up to the lateral edge of the pars palatina of the premaxilla.

The paired pterygoids are triradiate with distinct anterior, medial, and posterior rami. The anterior ramus is the longest and it extends almost parallel to the sagittal axis of the skull. It never contacts the palatine but reaches the maxilla through the pterygoid cartilage, from nearly the middle of the orbit to almost the level of the planum antorbitale. The medial ramus extends to the anteroventral surface of the prootic, never reaching the level of the parasphenoid ala. The posterior ramus joins the inner face of the squamosal. Pterygoids of Melanophryniscus alipioi, M. langonei, M. vilavelhensis, M. xanthostomus, and some specimens of $M$. krauczuki have a more delicate aspect, with relatively longer and slender anterior rami. More robust pterygoids are 

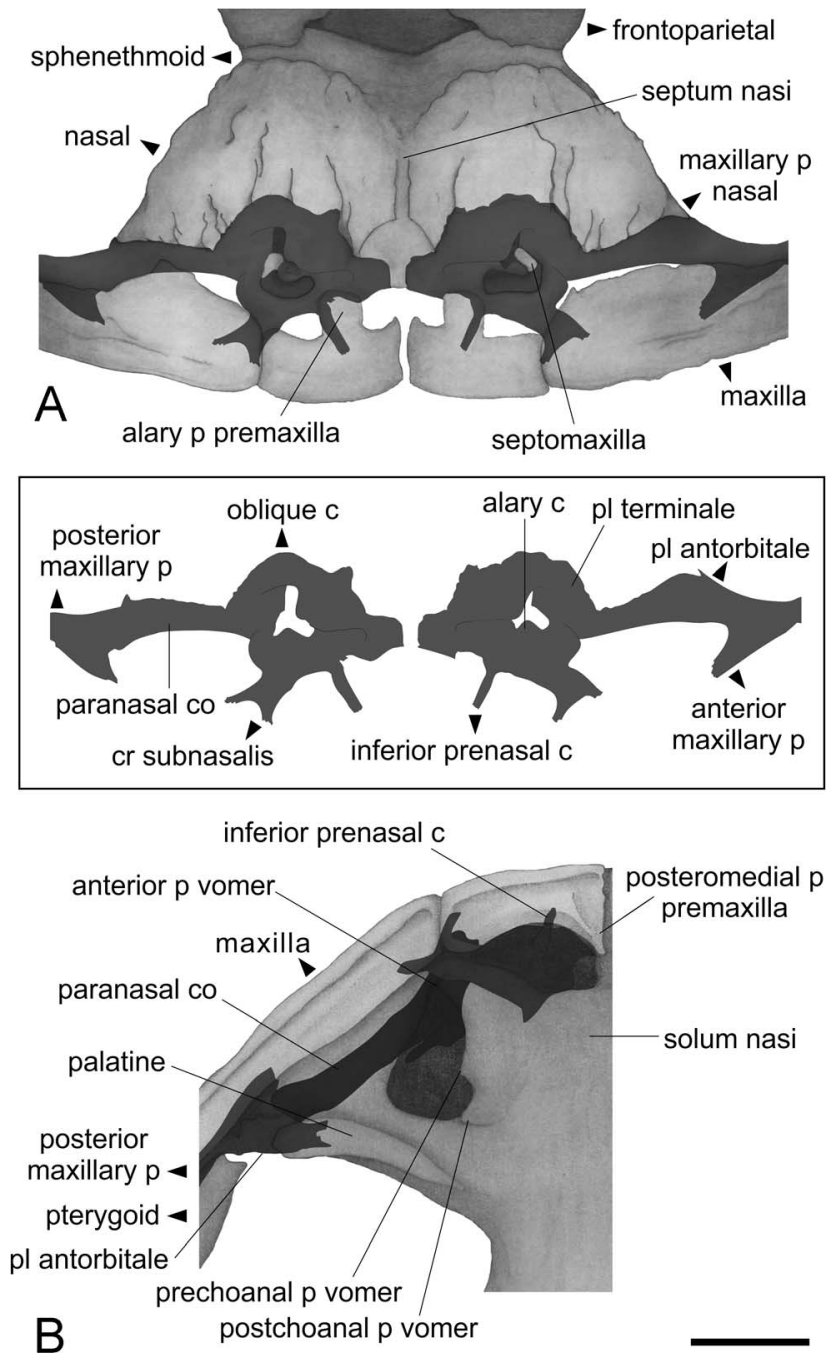

FIG. 4.-Nasal region of Melanophryniscus spectabilis (LGE 22700) in (A) frontal and (B) palatal views. Cartilage (solid grey), bone (shaded grey). c $=$ cartilage, $\mathrm{co}=$ commissure, $\mathrm{cr}=$ crista, $\mathrm{p}=$ process, $\mathrm{pl}=$ planum. Scale bar $=1 \mathrm{~mm}$.

characteristic of $M$. cambaraensis, M. devincenzii, $M$. estebani, M. pachyrhynus, M. paraguayensis, M. stelzneri, most specimens of $M$. aff. devincenzii, and some specimens of M. cupreuscapularis, M. klappenbachi, and M. rubriventris.

Lower jaw.-The lower jaw consists of four elements arranged in bilateral edentate, slightly curved arcs. On the elongate scaffold of Meckel's cartilages, endochondral mentomeckelians ossify rostrally, whereas angulosplenials and dentaries invest the medial and lateral surfaces, respectively (Fig. 7). Mentomeckelians are small and quadrangular, and articulate syndesmotically to each other through their barely expanded and concave medial surfaces. Dentaries extend posterolaterally for about three fourths the length of the mandible, and angulosplenials lack coronoid processes.

Suspensorium.- - In most specimens analyzed, the squamosals show only two rami-otic and ventral-oriented almost at a right angle (Fig. 8A). The otic ramus extends dorsally, contacting the lateral surface of the crista parotica. The ventral ramus is longer than the former and expands
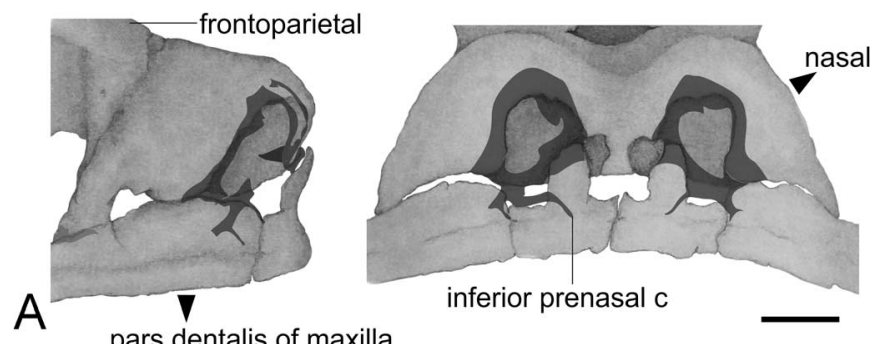

pars dentalis of maxilla
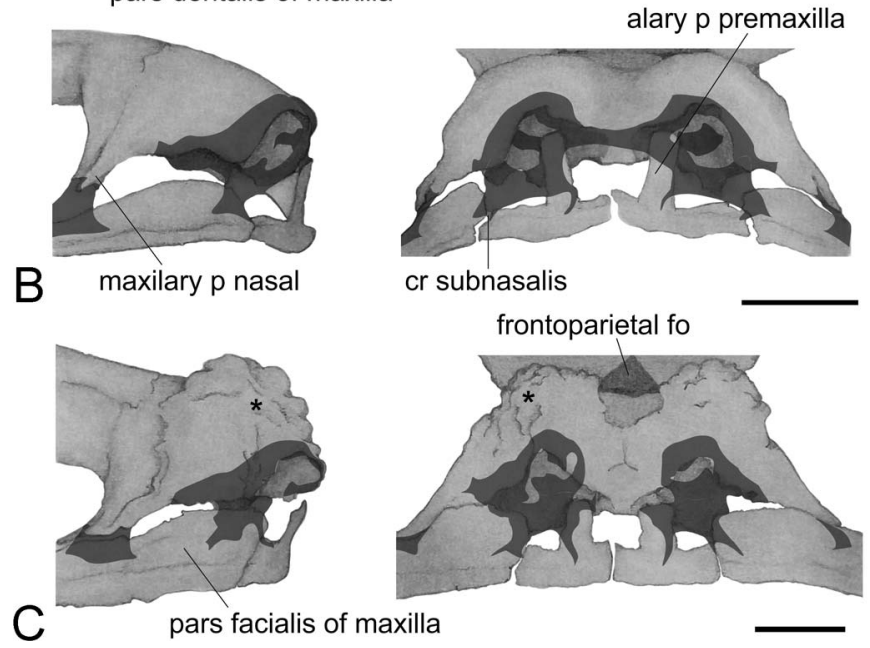

FIG. 5.-Nasal region of (A) Melanophryniscus rubriventris (FML 5083/ 1), (B) M. alipioi (DZUP 355), and (C) M. devincenzii (LGE 11060) in lateral (left) and frontal (right) views. Cartilage (solid grey), bone (shaded grey). $\mathrm{c}=$ cartilage, $\mathrm{cr}=$ crista, fo $=$ fontanelle, $\mathrm{p}=$ process. Note the sculptured surface of the nasals of $M$. devincenzii (asterisks). Scale bars $=1$ $\mathrm{mm}$.

ventrally, extending to the level of the mandibular arch. The pars articularis of the palatoquadrate is always visible as a thin, distal portion of cartilage. A small and slender bony projection is evident at the angle between the otic and the ventral rami of Melanophryniscus alipioi, M. estebani, $M$. devincenzii, and some specimens of $M$. cupreuscapularis (Fig. 8B). In M. aff. pachyrhynus, M. macrogranulosus, M. simplex, and some specimens of $M$. aff. devincenzii, $M$. aff. montevidensis, M. atroluteus, M. montevidensis, M. moreir$a e$, and M. spectabilis, a knob-like protuberance occurs at this place (Fig. 8C). These structures likely represent an incipient zygomatic ramus. In $M$. setiba, a conspicuous bony flange occupies more than half of the length of the anterior margin of the ventral ramus. Quadratojugals are very small and placed at a slightly medial position with respect to the ventral rami of the squamosal and anteroventral to the pars articularis of the palatoquadrate. They extend anteriorly without contacting the maxilla directly but through fibrous tissue.

\section{Hyolaryngeal Apparatus}

The hyoid consists of a cartilaginous plate and long, ossified posteromedial processes (Figs. 7, 9). The shape of the hyoid plate is highly variable both at intra- and interspecific levels. The hyalia are slender, curved, and define a wide, U-shaped hyoglossal sinus. Anteromedial processes are present in Melanophryniscus setiba and absent in most other species, but a flat ridge can be observed in $M$. aff. montevidensis, M. aff. pachyrhynus, M. devincenzii, $M$. 


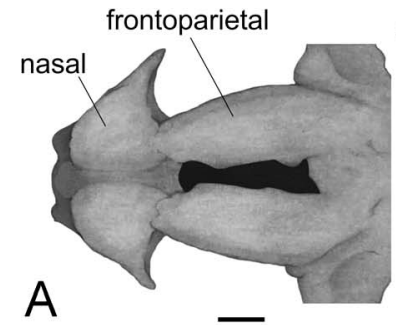

sphenethmoid

A

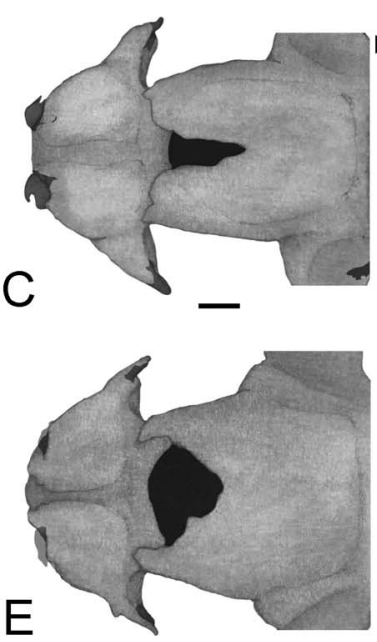

E

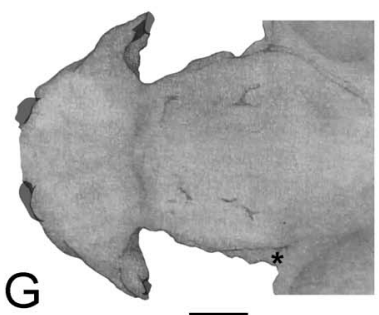

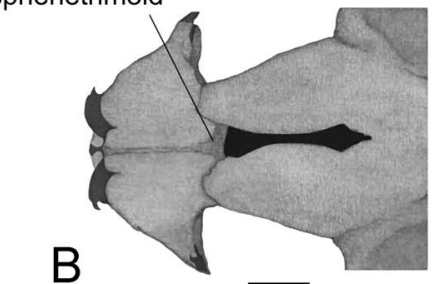
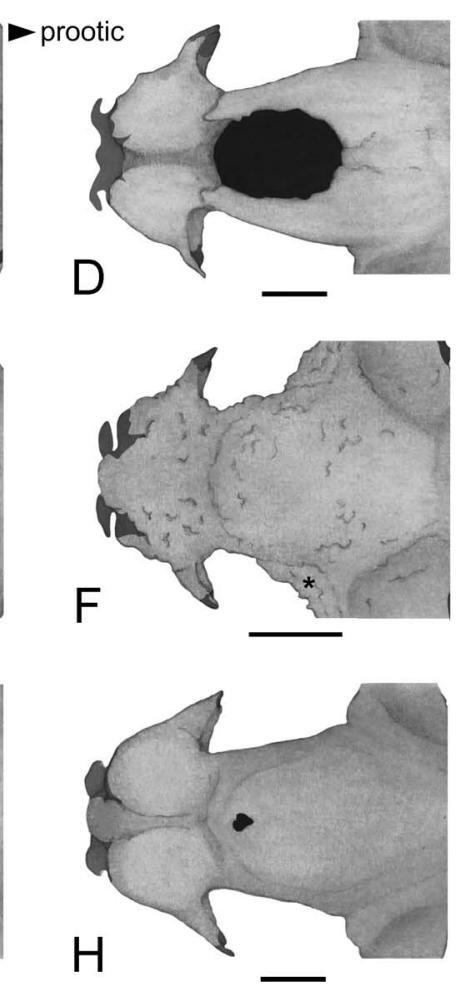

FIG. 6.-Detail of the dorsal skull of (A) Melanophryniscus rubriventris (LGE 22692), (B) M. montevidensis (MLP A. 1091), (C) M. cambaraensis (MCN 13473), (D) M. sanmartini (LGE 22693), (E) M. estebani (MACN 35405), (F) M. setiba (CFBH 15735), (G) M. klappenbachi (MLP A. 2268), and (H) M. cupreuscapularis (LGE 11049). Cartilage (solid grey), bone (shaded grey), and fontanelle (black). Note the exostosed frontoparietals of M. setiba and M. klappenbachi and the lateral bony excrescences that extend through the postorbital margin in these species (asterisks). Scale bars $=1$ $\mathrm{mm}$.

paraguayensis, M. stelzneri, M. xanthostomus, some specimens of M. alipioi, M. krauczuki, M. moreirae, $M$. rubriventris, $M$. spectabilis, and one specimen of $M$. klappenbachi. Lateral margins of the hyoid corpus may show at least three different arrangements. In M. alipioi and $M$. setiba, the corpus is narrow and long, and anterolateral (=alary) processes arrange on the anterior half and expand laterally (Fig. 9A,B). In M. langonei and M. sanmartini, in addition to the anterolateral process of a similar aspect, posterolateral processes are clearly differentiated. These arise from the posterior half of the margin and are pointed and caudally oriented (Fig. 9C,D). In all the remaining species, a broad, lateral cartilaginous sheet develops at the margins of the hyoid corpus. These lateral expansions may have different shapes. A slight cleft between anterior and posterior regions can be seen in M. krauczuki, M. simplex, and some specimens of $M$. aff. devincenzii, M. atroluteus, $M$. macrogranulosus, M. montevidensis, M. moreirae, M.

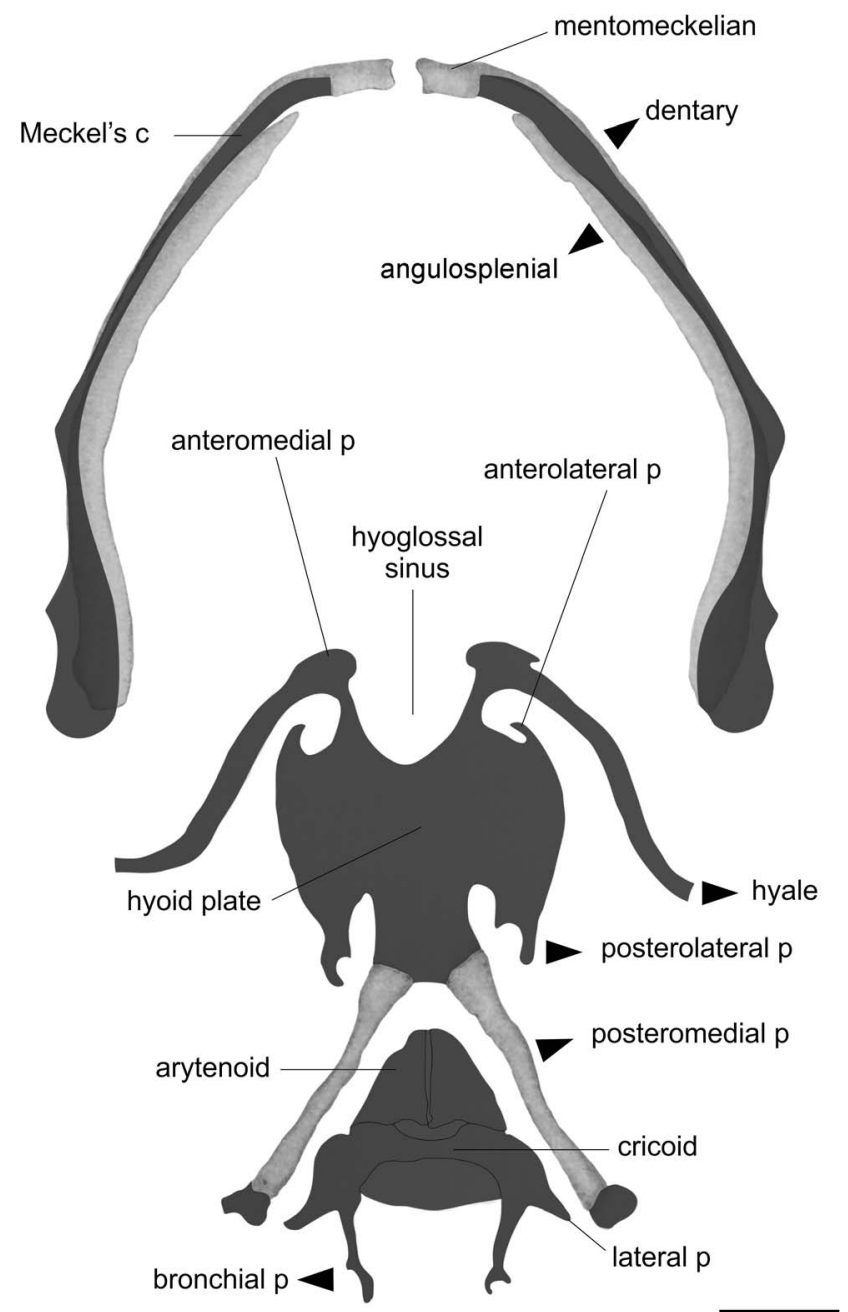

FIG. 7.-Lower jaw and hyoid apparatus of Melanophryniscus spectabilis (LGE 22700). Cartilage (solid grey), bone (shaded grey). $\mathrm{c}=$ cartilage, $\mathrm{p}=$ process. Scale bar $=1 \mathrm{~mm}$.

stelzneri, and M. rubriventris (Fig. 9E). A smooth margin characterizes M. admirabilis, M. aff. montevidensis, M. cambaraensis, M. devincenzii, M. fulvoguttatus, M. klappenbachi, and some specimens of $M$. aff. devincenzii, $M$. montevidensis, M. moreirae, and M. rubriventris. The contour of the hyoid plate lateral broadening of $M$. fulvoguttatus is unique, as it has both lobed anterolateral processes and posterolateral expansions. Besides this, the tip of the posterolateral process may be acutely pointed, bifurcate, or broad and rounded (Fig. 9F, G), and this varies both intra- and interspecifically. The posteromedial segment of the cartilaginous hyoid plate is partially mineralized in two specimens of $M$. cupreuscapularis.

Posteromedial processes are weakly sigmoid and bent dorsally and outwards. Proximally, they slightly expand and are separated from each other; distally, each posteromedial process ends in a small cartilaginous tip. These processes diverge laterally enough from the midline to accommodate the laryngeal cartilages.

The larynx is completely cartilaginous (Fig. 7). The arytenoids consist of a pair of valve-shaped cartilages. The cricoid forms a complete ring around the posteriormost part of the arytenoids; it bears a pair of short and pointed lateral 


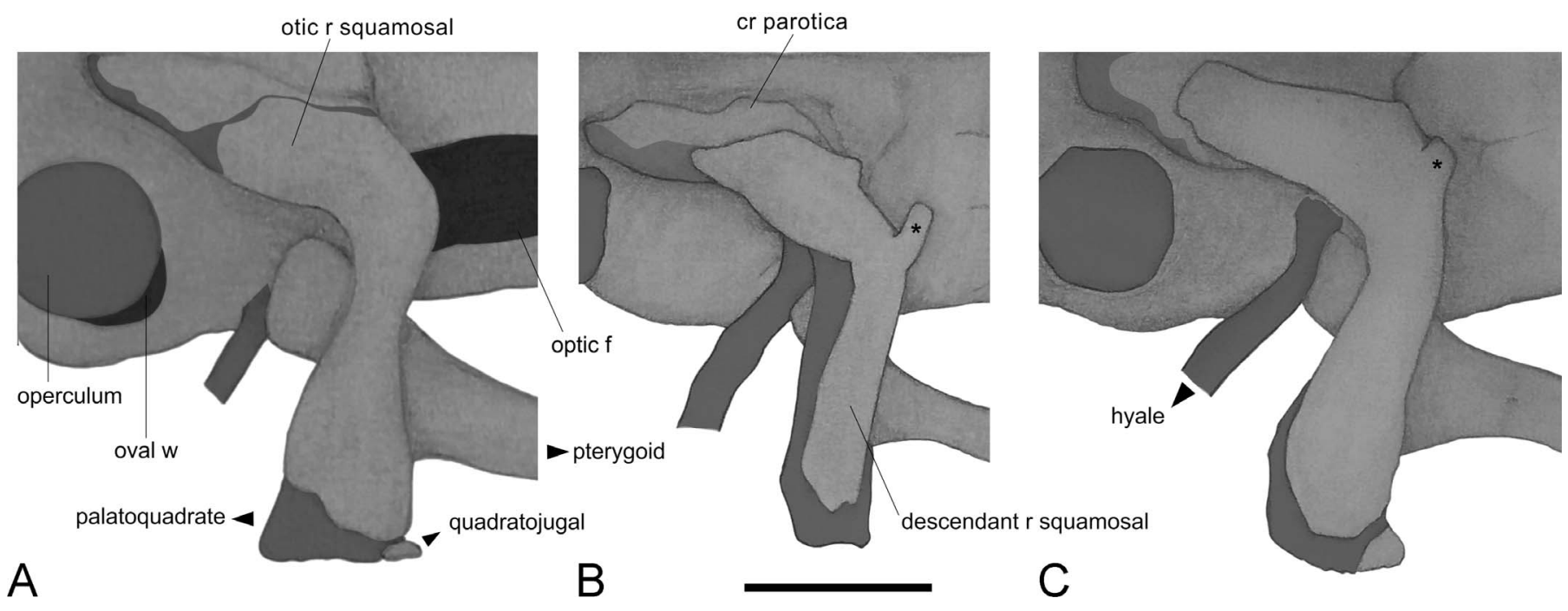

FIG. 8.-Lateral view of squamosals of (A) Melanophryniscus spectabilis (LGE 22700), (B) M. alipioi (DZUP 355), and (C) M. simplex (MCN 11057). Cartilage (solid grey), bone (shaded grey), and foramina or fenestrae (black). $\mathrm{cr}=\mathrm{crista}, \mathrm{f}=$ foramen, $\mathrm{r}=\mathrm{ramus}, \mathrm{w}=$ window. Note the incipient zygomatic ramus in some specimens (asterisks). Scale bar $=1 \mathrm{~mm}$.

processes and, if present, a pair of long and slender bronchial processes that run parallel to the longitudinal axis; the latter may curve and fork distally as observed in Melanophryniscus alipioi, M. devincenzii, M. spectabilis, and some specimens of M. aff. devincenzii, M. klappenbachi, M. rubriventris, and M. setiba. No bronchial processes are observed in $M$. sanmartini, $M$. stelzneri, and some specimens of $M$. montevidensis, likely because of damage during dissection. When present, the medial esophageal process is short and ranges from pointed to barely rounded.

\section{Axial Skeleton}

The vertebral column is composed of eight independent, procoelous, nonimbricate presacral vertebrae (excepting $M$. setiba with only six presacral independent elements), the sacral vertebra, and the urostyle. All these elements are entirely ossified (Figs. 10, 11). All vertebrae are wider than long. The centrum (vertebral body) is cylindrical. The neural channel is nearly rounded, wider in the anterior presacral region and flattening along the column in an anteroposterior way. The neural arches are entirely closed. In dorsal view, each vertebra has a well-developed neural spine that broadens posteriorly, reaching their maximum width at the caudal edge. More-conspicuous neural spines are documented in larger specimens (M. admirabilis, M. klappenbachi, $M$. macrogranulosus, and M. rubriventris). Pedicles may be as wide as the transverse processes (Fig. 11E,F). Presacral Vertebra I articulates with the occipital condyles through widely separated cotylar facets (cotylar arrangement Type I sensu Lynch 1971) and lacks prezygapophyses. A small posterior neural process provides an extra junction point between Presacral Vertebra I and the anterior edge of the neural spine of Presacral Vertebra II (Fig. 11A-D). Presacral vertebrae II-VIII have conspicuous prezygapophyses and postzygapophyses. The prezygapophyses of each vertebra articulate through the dorsal facets with the ventral surfaces of the postzygapophyses of the preceding vertebra. Postzygapophyses have a recurved contour in the articular view (Fig. 11E-J). Transverse processes exhibit different sizes and orientations (Fig. 10). Transverse processes of the Presacral Vertebra II point anterolaterally and are usually expanded or develop a spike-like projection at their posterolateral margin. Presacral Vertebra III presents the longest and more robust transverse processes; these are oriented at a right angle with the sagittal axis and may present jagged bony excrescences at their edges. Presacral Vertebra IV processes do not expand

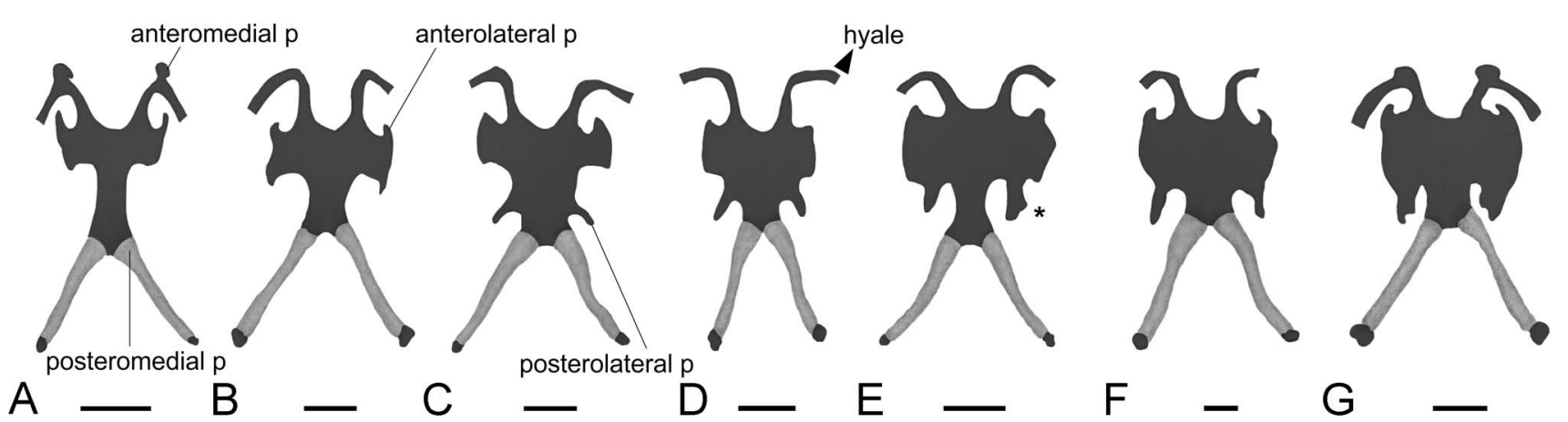

FIG. 9.-Hyoid apparatus of (A) male of Melanophryniscus setiba (CFBH 15745), (B) male of M. alipioi (DZUP 295), (C) male of M. sanmartini (LGE 22693), (D) male of M. langonei (LGE 23243), (E) female of M. moreirae (MLP A. 1806), (F) M. rubriventris (FML 2502), and (G) M. spectabilis (MCP 11927). Cartilage (solid grey), bone (shaded grey). $\mathrm{p}=$ process. Note the cartilaginous posterolateral processes of $M$. sanmartini and $M$. langonei, and the condition in M. moreirae (asterisk; see text). Scale bars $=1 \mathrm{~mm}$. 


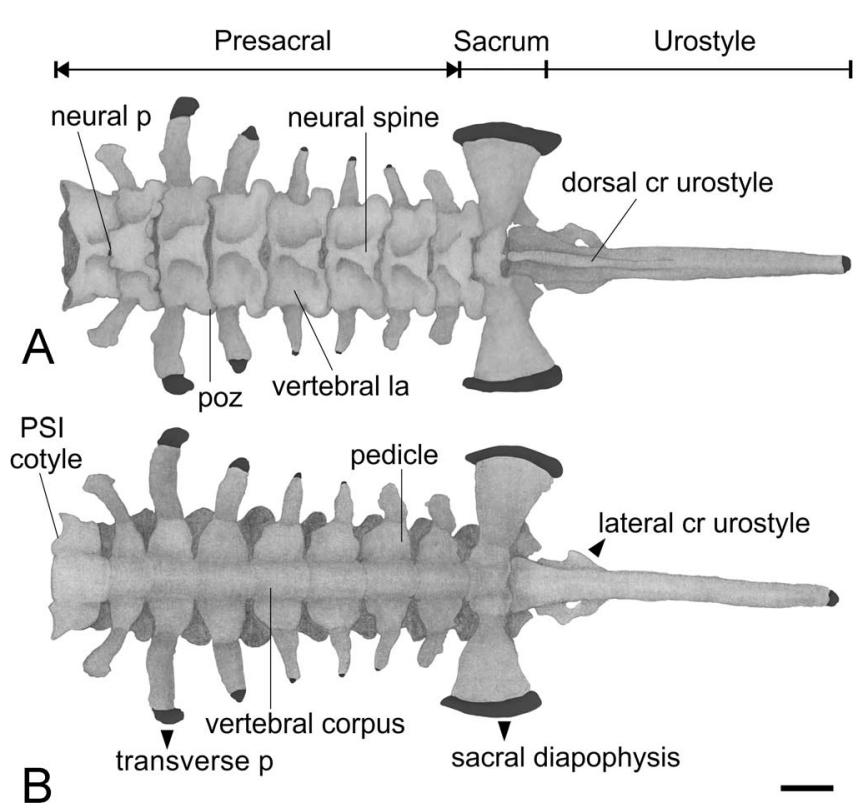

FIG. 10.-Vertebral column of Melanophryniscus spectabilis (LGE 22700) in (A) dorsal and (B) ventral views. Cartilage (solid grey), bone (shaded grey). $\mathrm{cr}=$ crest, la $=$ lamina, $\mathrm{p}=$ process, $\mathrm{poz}=$ postzygapophysis, $\mathrm{ps}=$ presacral vertebra. Scale $\mathrm{bar}=1 \mathrm{~mm}$.

distally. The relative length of the transverse processes of the presacral vertebrae and sacrum (sacral diapophysis) is generally III $\geq$ Sacrum $>$ IV $>$ II $\geq \mathrm{V} \geq \mathrm{VI} \geq \mathrm{VII} \approx$ VIII. Supernumerary presacral vertebrae are registered in one specimen of $M$. montevidensis. In a male of M. alipioi, presacral vertebrae VI and VII are fused to each other and an additional diapophysis emerges from the left side of a single vertebral body; a similar condition is seen in Presacral Vertebra VIII of the same specimen. Presacral vertebrae III and IV are fused in a female of M. estebani. In one specimen of $M$. aff. pachyrhynus, the left transverse process of Presacral Vertebra VIII is widened and has the aspect of the sacral diapophysis.

The sacrum articulates with Presacral Vertebra VIII through a pair of prezygapophyses and with the urostyle through a pair of rounded condyles (Fig. 10). Sacral diapophyses are distally expanded, adopting a triangular contour, and are oriented perpendicular to angled slightly backwards with respect to the sagittal axis. The distal ends of the sacral diapophyses are cartilaginous and overlie the anterior ends of the iliac shafts. In Melanophryniscus setiba, the sacrum is fused with Presacral Vertebra VII.

The urostyle is long and slender, uniformly wide along most of its length, and represents more than one third the extension of the column (urostyle length/column total length $=0.29-0.42[0.40 \pm 0.04] ;$ Fig. 10). It ends in a cartilaginous tip. When present, transverse processes form irregularly contoured crests on each side of the anterior quarter of the urostyle. Dorsally, a crest occurs throughout its anterior half and progressively diminishes in height toward its posterior end. The anterior tip of the dorsal crest surpasses the articular urostyle-sacrum margin and rests on a dorsal notch of the sacrum. In $M$. vilavelhensis, an additional vertebral element occurs between the sacrum and the urostyle. In one specimen of $M$. rubriventris the sacrum and urostyle are fused together in a single stiff element.

\section{Pectoral Girdle}

The pectoral girdle is composed of a series of ossified and cartilaginous elements that may exhibit different degrees of mineralization (Fig. 12A). The arrangement of the girdle elements matches conditions described by Kaplan (2004) as State A of epicoracoid fusion (in all taxa) plus varied extents of epicoracoid overlap, ranging from epicoracoids over-

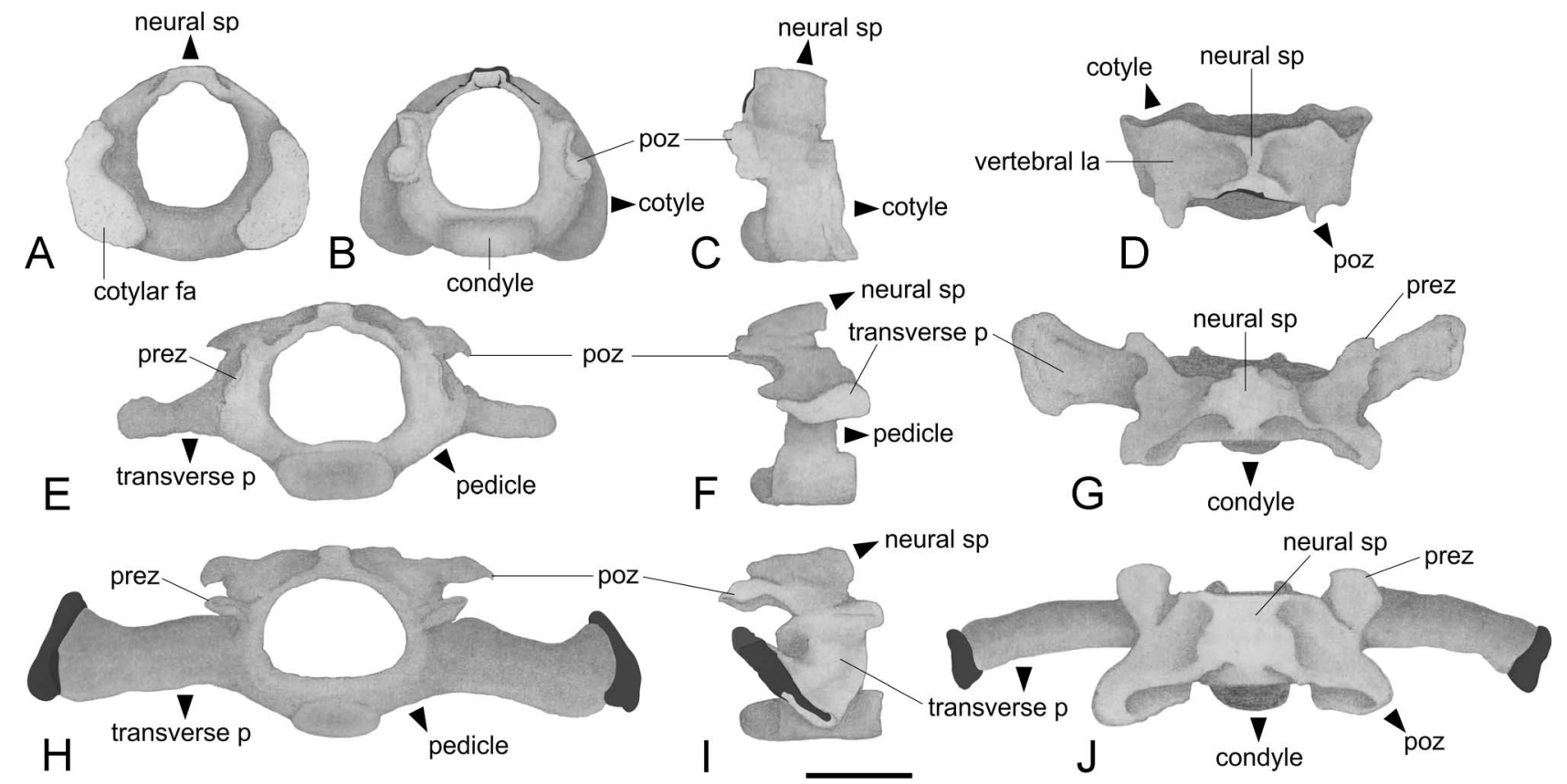

FIG. 11.-First presacral vertebrae of Melanophryniscus spectabilis (LGE 22700). Presacral Vertebra I in (A) anterior, (B) caudal, (C) lateral, and (D) dorsal views. Presacral vertebrae II and III in $(\mathrm{E}, \mathrm{H})$ anterior, $(\mathrm{F}, \mathrm{I})$ lateral, and $(\mathrm{G}, \mathrm{J})$ dorsal views. Cartilage (solid grey), bone (shaded grey). fa $=$ facet, la $=$ lamina, $\mathrm{p}=$ process, $\mathrm{poz}=$ postzygapophysis, prez $=$ prezygapophysis, $\mathrm{sp}=$ spine. Scale $\mathrm{bar}=1 \mathrm{~mm}$. 

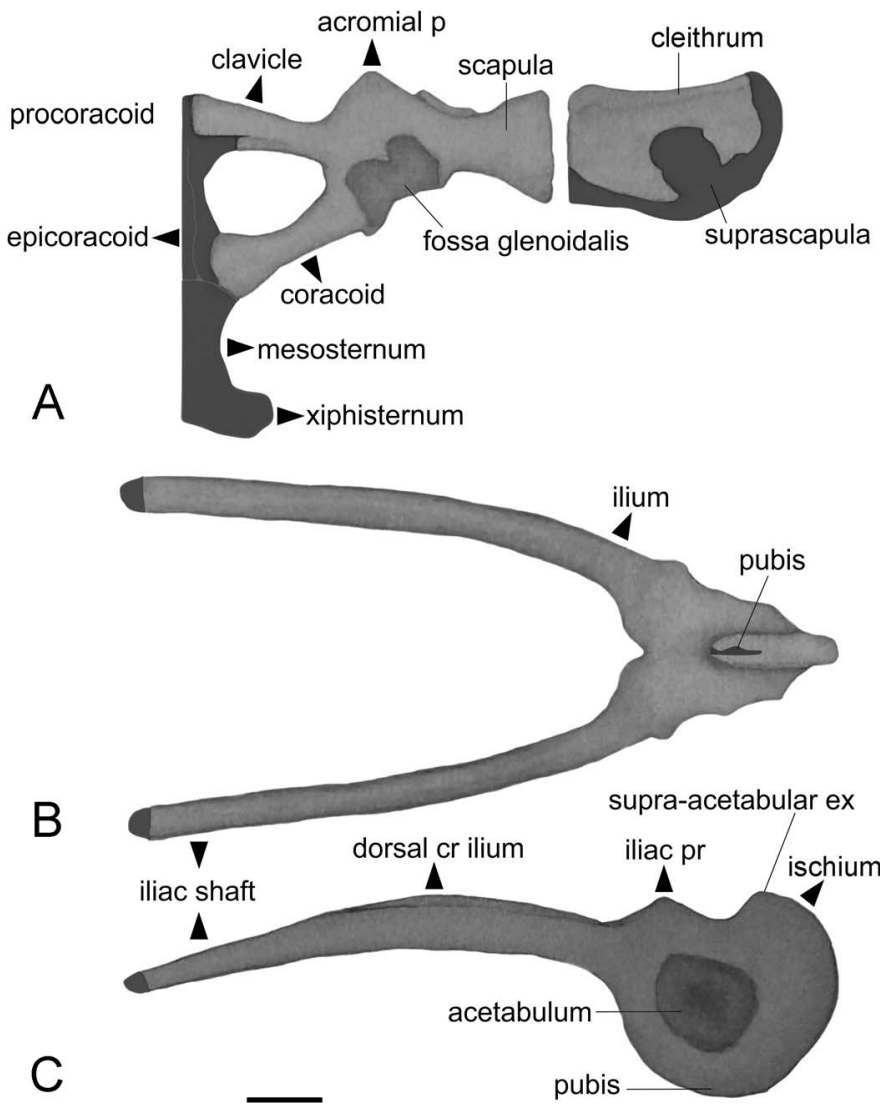

FIG. 12.-Girdles of Melanophryniscus spectabilis (LGE 22700). (A) Pectoral girdle in ventral view. Pelvic girdle in (B) ventral and (C) lateral views. Cartilage (solid grey), bone (shaded grey). $\mathrm{cr}=$ crest, $\mathrm{ex}=$ expansion, $\mathrm{p}=$ process, $\mathrm{pr}=$ protuberance. Scale $\mathrm{bar}=1 \mathrm{~mm}$

lapped along almost their whole extent (e.g., M. alipioi, M. sanmartini, and M. simplex), to epicoracoids overlapping along a very short, posterior region (M. atroluteus, M. krauczuki, and $M$. vilavelhensis). The sternal axis is composed of the cartilaginous procoracoid, epicoracoid, mesosternum, and xiphisternum and is slightly longer than the mediolateral extension of each side of the girdle (sternum length/pectoral girdle width $=0.46-0.79[0.60 \pm$ 0.07]). The mesosternum is calcified in M. cambaraensis, $M$. pachyrhynus, M. simplex, some specimens of $M$. aff. devincenzii, M. atroluteus, and single specimens of $M$. aff. montevidensis, M. cupreuscapularis, M. estebani, and M. stelzneri. The xiphisternum is commonly expanded and its abdominal margin may be convex ( $M$. aff. montevidensis, $M$. cupreuscapularis, M. krauczuki, M. langonei, M. sanmartini, M. simplex, most specimens of $M$. aff. devincenzii, and some specimens of M. rubriventris) or notched (M. pachyrhynus and $M$. xanthostomus). Both conditions are present in $M$. aff. pachyrhynus, M. alipioi, and M. klappenbachi. The omosternum is absent in all specimens examined. The pectoral fenestrae are teardrop-shaped, wider than long, and are delimited anteriorly by the procoracoids and the clavicles, medially by the epicoracoids and posteriorly by the coracoids. Each procoracoid is continuous with the epicoracoid, restricted to the posteromedial and medial sides of the clavicle, and progressively narrows to its lateral tip. Both sternal cartilages may remain cartilaginous or mineralize partially or completely, which may vary both intra- and interspecifically. In $M$. setiba, the sternum region lacks cartilage almost completely except for a slender region in the middle; in addition, mesosternum and xiphisternum are either absent or reduced to a small cartilaginous point in the posteromedial portion of the coracoid. The ossified coracoids, clavicles, and scapulae are fused together approximately at the level of the fossa glenoidalis. The clavicles are slightly thinner than the other elements. The coracoids are wider and dilated at the tips. The angle between clavicle and coracoid is highly variable inter- and intraspecifically. The scapulae are markedly wider at both their lateral and medial ends. The anterior and posterior margins of each scapula are concave; the anterior margin usually shows a bony excrescence, contiguous to the acromial point. A large foramen is present at the bottom of the glenoid cavity, likely indicating the medial junction of scapula, clavicle, and coracoid. The scapula articulates with the medial margin of the cleithrum and the suprascapula. The cleithrum and suprascapula form the distal region of the pectoral girdle. The anterior margin of the cleithrum is straight or slightly concave. The cleithrum and suprascapula vary in their degree of ossification and, in highly ossified specimens, the boundary between these elements is difficult to discern. The cleithrum ossifies at the anterior margin of this plate and grows posterior and laterally; it acquires a clear bilobate aspect in M. devincenzii, M. langonei, M. macrogranulosus, M. moreirae, M. sanmartini, and some specimens of M. alipioi and M. spectabilis. In M. klappenbachi both cleithrum and suprascapula are not distinguishable, forming a thick homogeneous lamina. A similar condition is observed in M. setiba, although structures can be discerned based on differences in alizarin reaction. In M. paraguayensis and some specimens of $M$. rubriventris, M. atroluteus, and M. cupreuscapularis, only a thin strip of cartilage remains at the lateral and posterior edges of the suprascapula.

\section{Pelvic Girdle}

Ischia and ilia are entirely ossified, and the pubis may remain cartilaginous (Melanophryniscus langonei), partially calcified (M. krauczuki and some specimens of M. alipioi and M. spectabilis), or completely calcified (all remaining taxa, Fig. 12B,C). The lines of suture between the pelvic elements may be distinguished in those specimens in which the pubis is not highly calcified, although they are commonly not discernible. Iliac shafts represent about three quarters of the total length of the girdle (iliac shaft length/pelvic girdle length $=0.63-0.78[0.69 \pm 0.02])$. Their anterior tips remain cartilaginous. A dorsal crest occurs at its posterior half and may reach half or more of the extension of the shaft, decreasing in height anteriorly, and sometimes bending medially at its anterior region. It represents more than half the length of the iliac shaft (iliac crest length/iliac shaft length $=0.42-0.76[0.58 \pm 0.06])$. The anterodorsal region of the ilium articulates with the ventral surface of the sacral diapophyses. Together, the internal edges of the ilia configure a closed U-shape; their divergence varies both intra- and interspecifically. Caudally the ilium expands, contributing to the anterior part of the acetabulum, and it exhibits an iliac protuberance dorsally (at the level of the anterior border of the acetabulum) and a preacetabular expansion ventrally. The angle between the iliac shaft and the preacetabular expansion varies from straight to slightly 
obtuse. In M. macrogranulosus, M. stelzneri, some specimens of $M$. aff. devincenzii and M. atroluteus, and one specimen of $M$. montevidensis and $M$. rubriventris, the preacetabular expansion slightly protrudes anteriorly. The ischia are convex on lateral view and bear a supra-acetabular expansion on its dorsal surface, posterior to the iliac protuberance and at the level of the posterior border of the acetabulum. Posterodorsally the ischium bears an interischiadic crest. The acetabulum is wide and circular (Fig. 12C).

\section{Forelimbs}

The humerus is the largest bone of the forelimb (Fig. 13A,B). The shaft is slightly curved. The caput humeri (glenoid epiphysis) is rounded and presents a conspicuous lateral notch. The eminentia capitata is visible as a large rounded structure in the distal epiphysis, located between the distal condyles. Both ulnar and radial epicondyles are rounded in ventral view. A deep notch is distinguishable between the ulnar epicondyle and the distal edge of the eminentia capitata, but only a faint groove appears at the junction of the latter and the radial epicondyle. The shaft bears a well-developed ventral crest (humeral ventral crest length/humerus length $=0.29-0.56[0.42 \pm 0.06])$ that originates near the proximal head of the humerus and runs as far as the middle of the diaphysis. It may bear a distinct groove all along its lateral surface, delimiting a flange along its edge. Two smaller crests, almost equal in extension, occur on the distal end of the bone opposite one another on the medial and lateral surfaces. A less developed proximo-medial crest may occur. The fossa cubitalis ventralis is wide and conspicuous. There is no noticeable sexual dimorphism in size or extension of the ventral crests in those species for which both sexes were available for study. Specimens of Melanophryniscus setiba have the largest humeral ventral crest of the genus, bifurcated by the presence of a spine, and the male of this species also has hypertrophied medial and lateral distal crests.

The radius and the ulna (Fig. 13C) are completely fused medially into a single structure that shows a distinct longitudinal groove (sulcus intermedius) from the distal head up to the midlength of the diaphysis. The ulna is longer than the radius (radius length/ulna length $=0.80-0.94[0.88$ $\pm 0.03]$ ), but both their diaphyses are almost equal in diameter. The olecranon (ulnar proximal head) and the capitulum (radius proximal head) are conspicuous and develop a concave articulation surface with the humeral eminentia capitata. The distal radial epiphysis is more voluminous than the ulnar epiphysis, and its articular surface is broader.

The autopodium has a set of carpal bones (ulnare, radiale, Element Y, Distal Carpal 2, Distal Carpal 3-4-5), four metacarpals and their corresponding phalanges (II to V) plus the prepollex, matching the Type $\mathrm{C}$ carpal morphology proposed by Fabrezi (1992; Fig. 13D). The radiale is almost trapezoidal, larger than the ulnare. The Element $\mathrm{Y}$ has a medial position with respect to the radial bone. It is saddleshaped and oriented in a proximal-distal direction. The fused element representing Carpal $3-4-5$ is the most voluminous of the distal carpal bones. It has three protuberances on its distal surface that fit the proximal articulation surfaces of metacarpals III, IV, and V, respec-
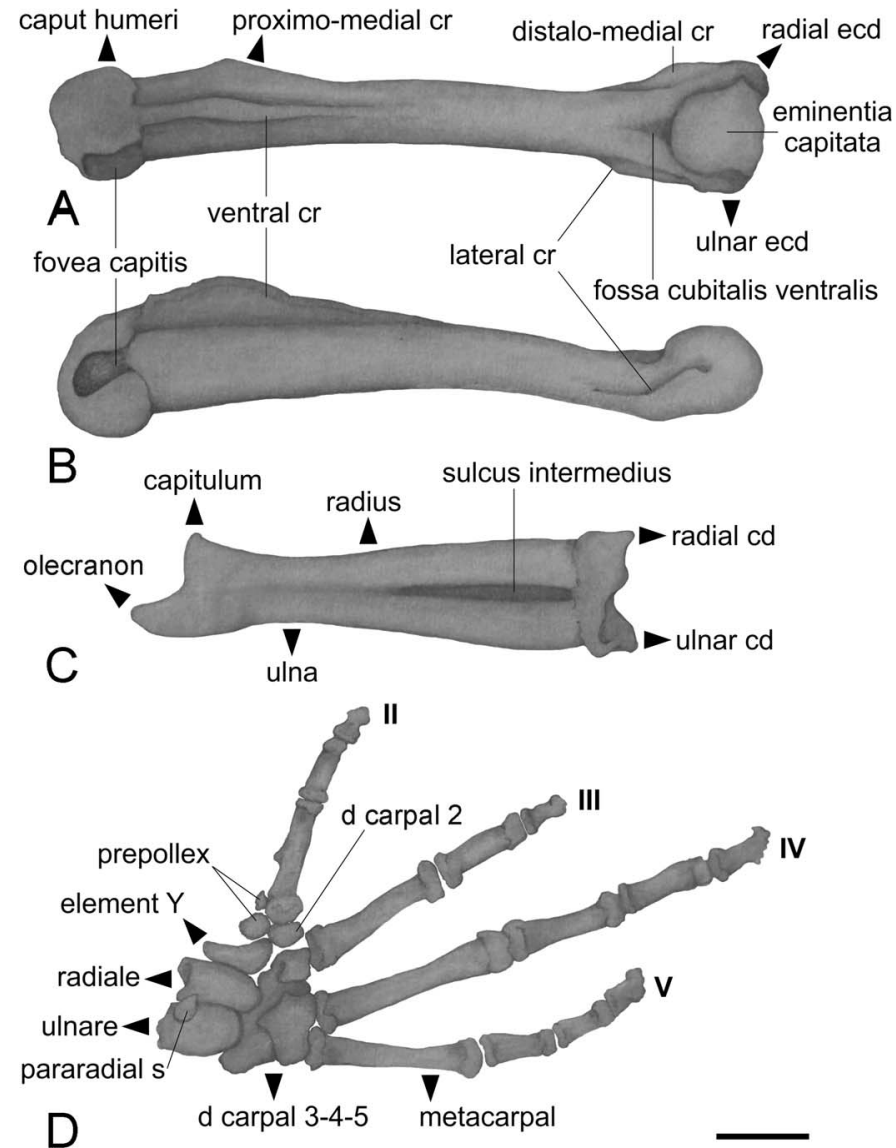

FIG. 13.-Right forelimb of Melanophryniscus spectabilis (LGE 22700). (A) Ventral and (B) lateral views of the humerus, (C) lateral view of the radioulna, and (D) dorsal view of the manus. $\mathrm{cd}=$ condyle, $\mathrm{cr}=$ crest, $\mathrm{d}=$ distal, ecd $=$ epicondyle, $\mathrm{s}=$ sesamoid. Scale bar $=1 \mathrm{~mm}$.

tively. The metacarpals are long $(\mathrm{IV}>\mathrm{V} \approx \mathrm{III} \approx \mathrm{II})$ and expanded at their tips. The Metacarpal II may exhibit a bony excrescence with variable position and length. In M. setiba, this excrescence extends all over the length of the metacarpal lateral surface, forming a conspicuous lamina that also seems to involve the distal element of the prepollex. Phalangeal formula in most species is 2-2-3-3, with finger relative lengths IV $>\mathrm{V}>$ III $>$ II. Conversely, the phalangeal formula in Melanophryniscus setiba is 1-2-3-2 and relative finger lengths are IV $>$ III $>$ V > II, with the single element of the second finger tightly jointed to the Metacarpal II. The distal phalanges are expanded distally and present a slightly concave, serrated edge. The prepollex may be formed by a single small, rounded bone or by two elements. In this latter case, the distal element is always smaller and its shape may vary (Fig. 14A-C). Examined specimens of M. sanmartini have an elongated, spine-like distal prepollical element made of cartilage (Fig. 14A). The prepollex of M. macrogranulosus consists only of the proximal prepollical element (Fig. 14D). In $M$. setiba, when present as a discrete element, the prepollex consists of the proximal element only.

\section{Hind Limbs}

The femur is a slim and weakly sigmoid bone, with a rounded caput femoralis that fits into the acetabulum of the pelvic girdle and a bicondylar distal head that articulates with 


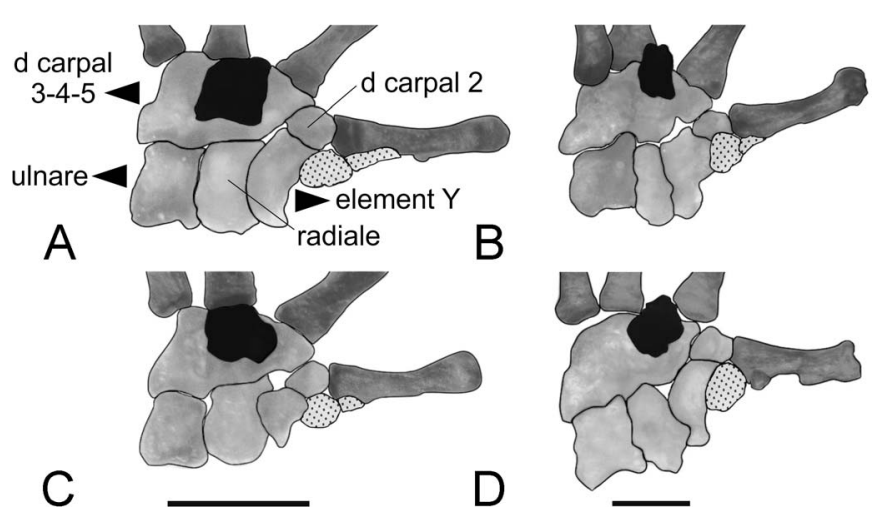

FIG. 14.-Detail of the basipodium and metapodium of the right manus in ventral view of (A) Melanophryniscus sanmartini (LGE 22693), (B) M. cambaraensis (MCN 13473), (C) M. atroluteus (LGE 09536), and (D) M. macrogramulosus (MCN 13818). Carpals (light grey), metacarpals (dark grey), prepollex (dotted), and palmar sesamoids (black) are indicated. $\mathrm{d}=$ distal. Scale bars $=1 \mathrm{~mm}$.

the proximal epiphysis of the tibiofibula (Fig. 15A). The femoral crest can reach approximately one fifth of the femur length.

The fusion between tibia and fibulae is only discernible by the presence of a distinct sulcus intermedius. A nutritional foramen perforates the bone diagonally at approximately the midpoint of the diaphysis. The tibiofibula is as long as the femur (tibiofibula length/femur length $=0.89-1.15[1.00 \pm$ $0.04]$ ). It is slender at its midpoint and expands progressively toward its epiphyses. The proximal fibular epiphysis is slightly longer than the proximal tibial epiphysis and bears a short crest that slightly infringes the diaphysis (Fig. 15B,C).

The autopodium consists of a series of tarsal elements (tibiale, fibulare, and three distal elements), five metatarsal
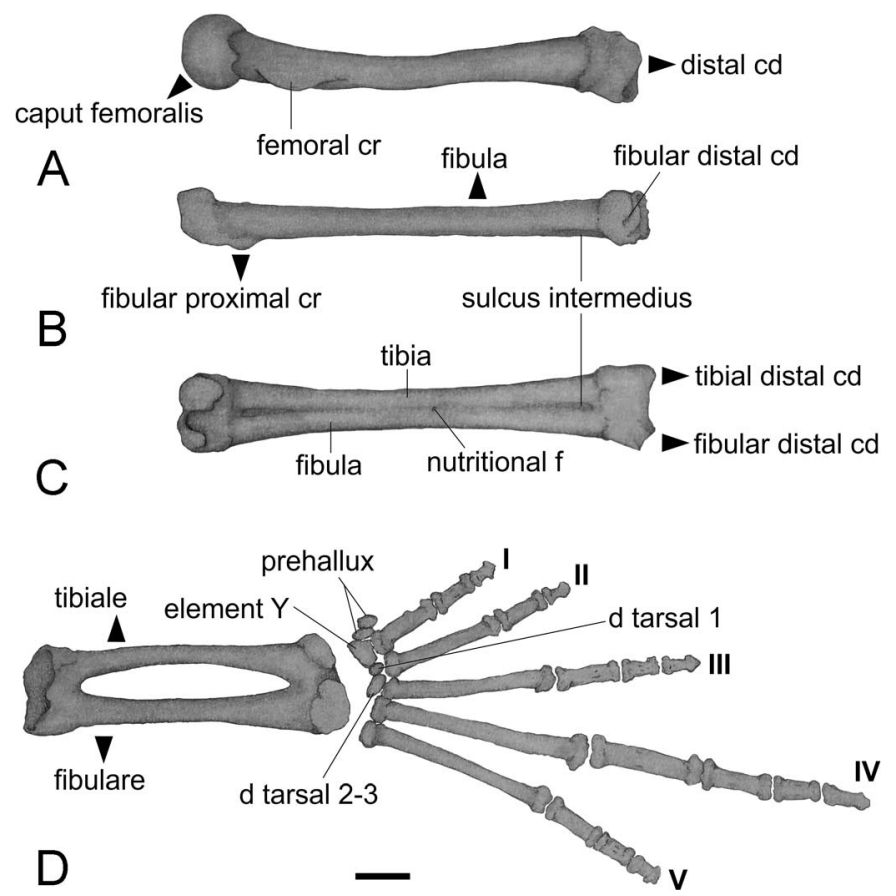

FIG. 15.-Right hind limb of Melanophryniscus spectabilis (LGE 22700). (A) dorsal view of the femur, (B) fibular, and (C) medial views of the tibiofibular, and (D) dorsal view of the pes. $\mathrm{cd}=$ condyle, $\mathrm{cr}=$ crest, $\mathrm{d}=$ distal, $\mathrm{f}=$ foramen. Scale bar $=1 \mathrm{~mm}$.

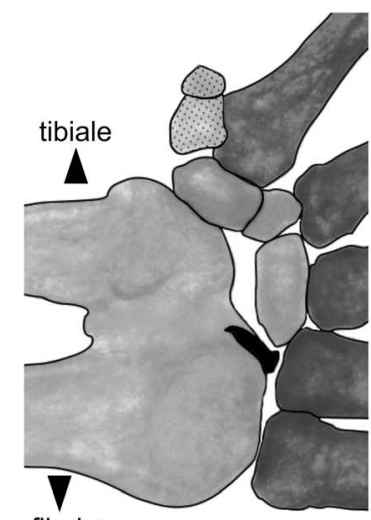

fibulare

A

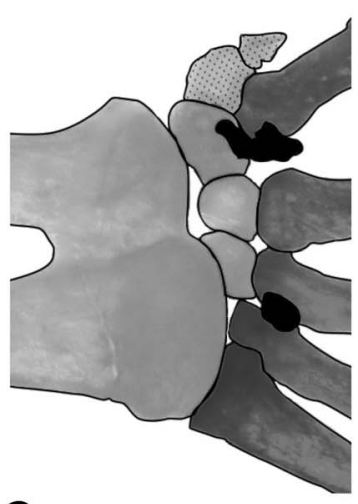

C

FIG. 16.-Detail of the basipodium and metapodium of the left pes in plantar view of (A) Melanophryniscus aff. devincenzii (LGE 22695), (B) M. sanmartini (LGE 22693), (C) M. rubriventris (LGE 21222), and (D) M. xanthostomus (CFBH 41993). Tarsals (light grey), metatarsals (dark grey), prehallux (dotted), and plantar sesamoids (black) are indicated. $\mathrm{d}=$ distal. Note variation in size and fusion of elements. Scale bars $=1 \mathrm{~mm}$.

elements and corresponding phalanges (I to V), and the prehallical elements (Fig. 15D). This configuration is congruent with that described by Fabrezi (1993) for bufonids (see also Fabrezi 2001). The tibiale and fibulare are almost equal in length and represent more than $65 \%$ of the tibiofibula extension (tibiale-fibulare length/tibiofibula length $=0.55-0.76[0.66 \pm 0.03])$. They are fused at their proximal and distal epiphyses. The relative sizes of the distal elements of the tarsus vary (Fig. 16). The Element Y locates proximal to the Metatarsal I and articulates medially with the proximal element of the prehallux and laterally with the Distal Tarsal 1. The Distal Tarsal 1 articulates with Metatarsal II and may contact Metatarsal I in some specimens (Fig. 16A,B). The Distal Tarsal 2-3 is aligned with Metatarsal III, it articulates medially with the Distal Tarsal 1 and, in general, it is transversely elongated. In one specimen of $M$. rubriventris, three elements could be interpreted as Element $\mathrm{Y}$ fused to Distal Tarsal 1 and independent distal tarsals 2 and 3 (Fig. 16C). In one hand of the single specimen of $M$. xanthostomus, two voluminous elements likely represent fused Element Y + Distal Tarsal 1, and distal tarsals $2+3$, or Element $\mathrm{Y}$ and distal tarsals 1-3 (Fig. 16D). Metatarsals IV and V abut directly at the surface of the distal epiphysis of the tibiale. The metatarsals are long 
TABLE 3.-Postcranial sesamoids in Melanophryniscus. The lack of sesamoids in the specimen of $M$. paraguayensis is surely an artifact of preparation; data of $M$. setiba are taken from the literature.

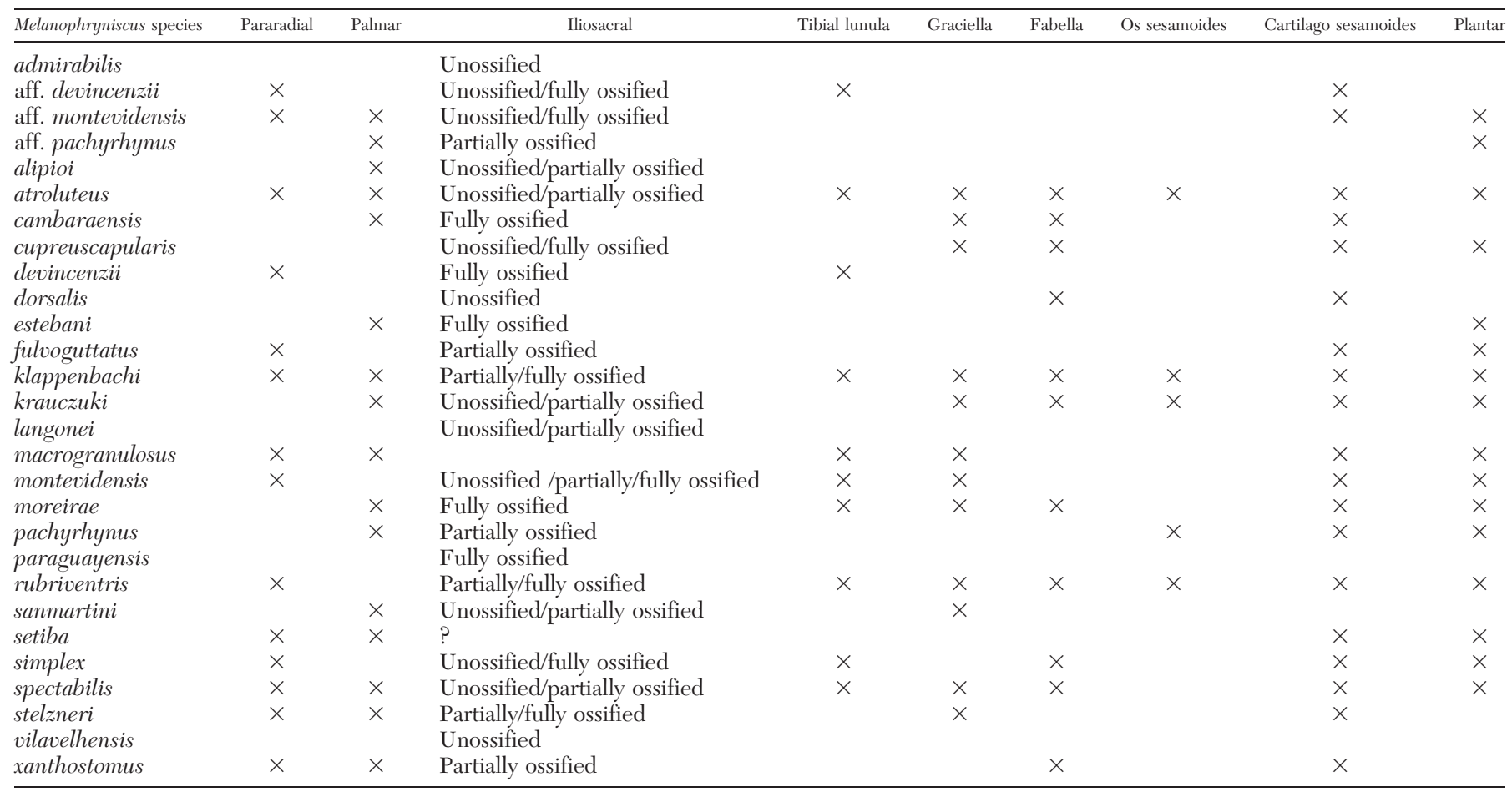

and follow the formula IV $>\mathrm{V} \approx$ III $>$ II $>$ I. The phalangeal formula is 2-2-3-4-3, and the relative length of the toes is $\mathrm{IV}>\mathrm{V} \approx \mathrm{III}>\mathrm{II} \approx \mathrm{I}$. The phalangeal formula is reduced and sexually dimorphic in $M$. setiba (1-2-2-4-2 in males and 1-2-3-4-2 in females; Peloso et al. 2012). In all species, distal phalanges are expanded at their distal tips and have serrated edges. The prehallux commonly has two elements (Fig. 16A-C). When present, the distal prehallical element is usually smaller and variable intra- and interspecifically, both in shape and extent of mineralization (e.g., longer and slender in $M$. aff. pachyrhynus, but much reduced in some specimens of $M$. rubriventris and $M$. montevidensis; cartilaginous and approximately of the same size of the proximal element in M. sanmartini; see Fig. 16). In M. xanthostomus and one specimen of M. alipioi, only one prehallical element is observed, although we cannot rule out unintended damage during specimen preparation (Fig. 16D).

\section{Sesamoids}

We report the presence of sesamoids in pelvic girdle and limbs. This survey is certainly flawed, because several specimens were already disarticulated, and fibrous tissue where sesamoids are embedded was mostly removed during preparation. However, we found a maximum of nine elements across 75 specimens of most of the species (Table 3). Sacral sesamoid is usually located near the midpoint of the distal edge of the sacral diapophysis; it varies in arrangement, shape, and calcification extent at intra- and interspecific levels. In Melanophryniscus langonei, for instance, it may be elongated or slightly curved, cartilaginous or robust and partially calcified, and be placed at the middle of the diapophyseal margin or slightly shifted forward.
Rather than a discrete, conspicuous element as in most specimens, a diffuse cartilaginous field was observed in one specimen of M. krauczuki.

In forelimbs, two sesamoids are present, one at the dorsal surface of the joint between the radiale and the distal radial epiphysis and the second one on the ventral surface of the autopodium, approximately at the level of the Carpal 3-4-5. They correspond to pararadial and palmar sesamoids, respectively. The pararadial is a relatively small, ovoidal or subtriangular sesamoid, and we recorded it in Melanophryniscus fulvoguttatus, some specimens of $M$. atroluteus, $M$. klappenbachi, M. rubriventris, M. simplex, one specimen of M. spectabilis, M. aff. devincenzii, M. stelzneri, etc. (Figs. 13D, 17A). The palmar is a large, calcified element seen in M. sanmartini, some specimens of $M$. aff. pachyrhynus, $M$. alipioi, M. atroluteus, M. cambaraensis, M. krauczuki, and single specimens of $M$. moreirae, M. pachyrhynus, $M$. macrogranulosus, M. stelzneri, M. spectabilis, M. xanthostomus, etc. (Fig. 14). In hind limbs, three sesamoids are located at the femoral-tibiofibular joint: the tibial lunula, graciella, and fabella (Fig. 17B,C). Two or three more occur on the ventral surface of the foot: the cartilago sesamoides and one or two plantar sesamoids (Fig. 17D). The tibial lunula is the largest and most internal of the knee joint sesamoids; it is an entirely ossified biconcave element observed in specimens of M. klappenbachi, M. macrogranulosus, M. rubriventris, M. simplex, M. spectabilis, etc. The graciella is observed in the popliteal region of the knee joint as a relatively smaller sesamoid, slightly displaced toward the femoral epicondyle-proximal tibial epiphysis articulation. It is recorded in M. rubriventris, M. cambaraensis, M. sanmartini, M. spectabilis, and single specimens of M. macrogranulosus, M. pachyrhynus, M. stelzneri, etc. The 

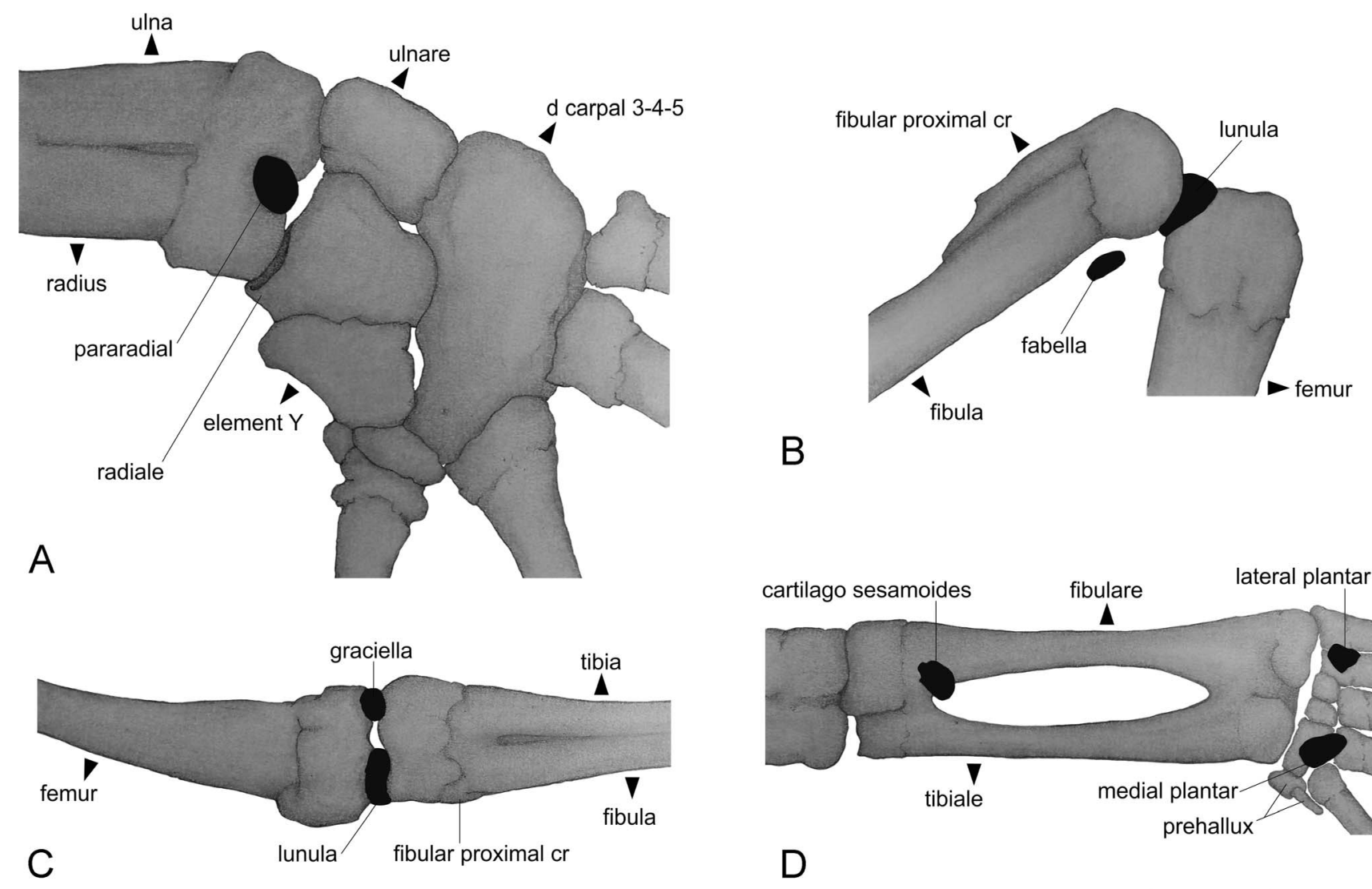

B

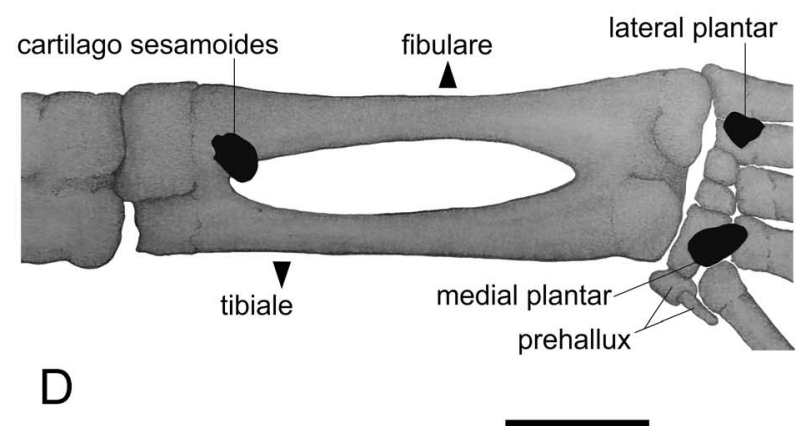

FIG. 17.-Detail of the sesamoids found in Melanophryniscus. (A) Dorsal view of the left forelimb radioulna-carpal joint of M. rubriventris (FML 1477/2), (B) lateral view of the left knee-joint of M. rubriventris (FML 5083/1), (C) ventral view of the left knee-joint of M. spectabilis (MCP 11927), and (D) plantar surface of the right pes of $M$. aff. devincenzii (LGE 11059). Sesamoids are highlighted in black. cr $=$ crest, $\mathrm{d}=$ distal. Scale bar $=1 \mathrm{~mm}$.

fabella occurs in a more external position of the popliteal region as a small rounded or barely elongated sesamoid embedded in the proximal tendon of the m. gastrocnemius; it is observed in some specimens of $M$. rubriventris and $M$. krauczuki and in single specimens of M. klappenbachi and M. xanthostomus, among others. The cartilago sesamoides occurs on the ventral side of the proximal tibial-fibular epiphysis in some specimens of M. atroluteus, M. klappenbachi, M. krauczuki, M. rubriventris, and in single individuals of $M$. aff. montevidensis, $M$. cambaraensis, $M$. pachyrhynus, etc. Finally, one or two sesamoids occur on the sole of the foot at the proximal region of metatarsals: one of them on the proximities of the base of Metatarsal IV (e.g., in M. estebani, M. fulvoguttatus, and some specimens of $M$. aff. pachyrhynus, M. atroluteus, M. krauczuki, and M. macrogranulosus) and the other in a more medial position near the base of the metatarsals $\mathrm{I}-\mathrm{II}$ and the Element $\mathrm{Y}(M$. xanthostomus, and some specimens of $M$. aff. devincenzii, M. rubriventris, M. simplex, and M. spectabilis; Figs. 16, 17D). In single specimens of M. atroluteus, M. klappenbachi, M. krauczuki, and M. rubriventris, a likely calcified region is seen on the fibrous aponeurosis of the heel in a more external position relative to the cartilago sesamoides; this likely corresponds to the os sesamoides.

Main qualitative differences in cranial and postcranial skeleton surveyed in paragraphs above are summarized in the scheme of Figure 18.

\section{Morphometric Variation in the Genus}

Results of the principal component analyses performed on skeletal measurements are given in Tables 4 and 5 and Figure 19. Although we explored the components with eigenvalues higher than 1.0 and the highest variances, we interpret only the first two because main patterns of absolute size and shape variation of species groups are already evident. In the analysis on raw measurements, the ordination of the first two components (together explaining ca. 94\% of the total variance; Table 4) is, as expected, almost exclusively structured by size-related variations (loadings on first component $>0.79$ in all variables; Table 5). Species arrange along the first component from small species of the Melanophryniscus moreirae group plus early branching $M$. setiba to the largest species that include M. admirabilis and M. rubriventris (M. stelzneri group), and M. cambaraensis, M. macrogranulosus, and M. pachyrhynus (M. tumifrons group; Fig. 19A). In the size-corrected analysis, shape differences between species are revealed, and segregation of intrageneric groups is evident (Fig. 19B). The first principal component (17\% of the total variance; Table 4 ) is explained mainly by variations in length of long bones of limbs, height of supra-acetabular depression and iliac protuberance (indicative of ilium body height), and width of presacral vertebrae IV-VI (factor loadings higher than 0.60 in Table 5); M. tumifrons and M. stelzneri show largely overlapping ranges of variation and species of the $M$. moreirae group differ from early branching species by 

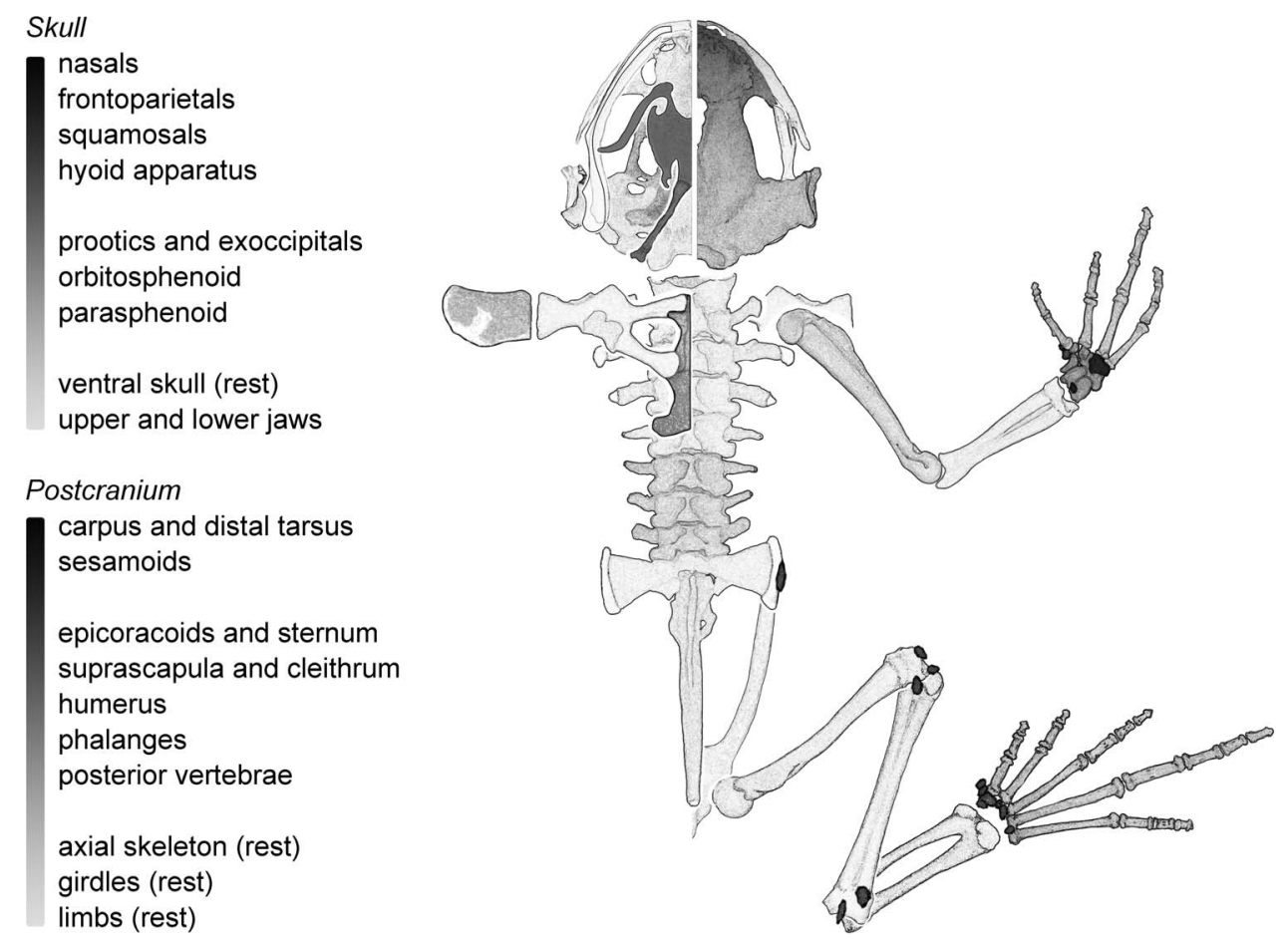

FIG. 18.-Summary scheme of qualitative variations (e.g., presence, shape, ossification extent) in cranial and postcranial skeleton of species of Melanophryniscus. Dorsal (right) and ventral (left) views of the skeleton are combined to show main elements; limb sesamoids, visible from different views, are shown overlapped in dorsal view. Shades highlight zones with high (dark grey) to low (light grey) variation, as discussed in text. Most elements are variable across all species, excepting the humerus and phalanges that vary only in M. setiba. Sesamoids appear as highly variable but, as commented in text, this should be checked with larger sampling.

having in general longer limb bones, higher ilium body, and narrower posterior presacral vertebrae. In addition, species of the M. tumifrons group differ from the other three groups by the lower scores on the second principal component (12\% of the total variance; Table 4), correlated with shorter presacral vertebrae II-V (factor loadings higher than 0.55 in Table 5).

\section{Discussion}

Skeletal descriptions of Melanophryniscus species have been documented since the last quarter of the 19th Century, but it was not until almost $100 \mathrm{yr}$ later that a few researchers addressed the osteological variation of the genus in a more taxonomically inclusive scenario. Some of these studies were part of the first precladistic and cladistic approaches to solving the taxonomic status of the Neotropical clades of bufonids (McDiarmid 1971; Cannatella 1986; Graybeal and Cannatella 1995). In his substantial contribution based on 16

TABLE 4.-Results of principal component analyses on raw and sizecorrected measurements. Eigenvalues, variances, and cumulative variances are detailed for the first two components and summarized for the rest.

\begin{tabular}{lccc}
\hline Principal component & Eigenvalue & Variance $(\%)$ & Cumulative variance (\%) \\
\hline Raw measurements & & & \\
1 & 43.2612 & 91.58 & 91.58 \\
2 & 0.8593 & 1.81 & 93.40 \\
$3-49$ & $0.7741-0.0006$ & $1.63-0$ & $95.04-100$ \\
Size-corrected measurements & & \\
1 & 8.2756 & 16.89 & 16.89 \\
2 & 5.6702 & 11.57 & 28.46 \\
$3-49$ & $4.6725-0.0028$ & $9.53-0$ & $37.99-100$ \\
\hline
\end{tabular}

major characters, including several osteological traits (e.g., type of vertebrae, shape of coccyx, number of presacral vertebrae, type of pectoral girdle, shape of sacral diapophyses, absence of maxillary and vomerine teeth, and presence of sternum), McDiarmid (1971) linked the former "Atelopodidae" (excepting Brachycephalus) with the family Bufonidae. Considering that the species richness of Melanophryniscus was then represented by less than half the species known today, and that those studies concluded that informative characters came from the skull, a more complete revision of traits proposed as diagnostic for the genus has long been in order. Our observations increase the knowledge of the osteology of those species whose skeletons were not formerly described or whose descriptions were incomplete or insufficiently detailed.

Exhaustive analyses of the adult osteology of Melanophryniscus reveal a relatively conservative plan, and variations do not have a clear correspondence with the intrageneric structure of the group. Polymorphisms are quite common throughout the genus. Only M. setiba has very divergent skeletal features, including quantitative (e.g., number of presacral vertebrae, phalangeal formulae) and qualitative aspects (e.g., exostosis of nasals and frontoparietals, strongly reduced sternal elements, hypertrophy of the humeral crests and autopodial bones; Peloso et al. 2012). Size variation largely structures interspecific diversity in the genus. Although we did not explore this in a proper phylogenetic context, a pattern of body size evolution can be interpreted from measurement ordination. From smallsized early diverging species and members of the $M$. moreirae group, morphological diversification of the genus 
TABLE 5.-Results of principal component analyses on raw and size-corrected measurements. Loadings of raw and size-corrected measurements on principal components (only the two first components are shown) are presented. In raw analysis, all measurements are highly correlated ( $>0.79$ ) with principal component 1; in size-corrected analysis, higher loadings are indicated in bold.

\begin{tabular}{|c|c|c|c|c|}
\hline \multirow[b]{2}{*}{ Character } & \multicolumn{2}{|c|}{ Raw measurements principal components } & \multicolumn{2}{|c|}{ Size-corrected measurements principal components } \\
\hline & 1 & 2 & 1 & 2 \\
\hline Skull length & 0.96 & 0.07 & 0.18 & 0.23 \\
\hline Skull maximum width & 0.95 & 0.03 & 0.14 & -0.20 \\
\hline Antorbital width & 0.92 & 0.09 & -0.04 & -0.08 \\
\hline Postorbital width & 0.94 & 0.09 & -0.04 & 0.21 \\
\hline Condylar width & 0.92 & 0.02 & 0.19 & 0.12 \\
\hline Premaxilla length & 0.91 & 0.00 & 0.34 & 0.08 \\
\hline Premaxilla width & 0.86 & 0.03 & 0.31 & 0.19 \\
\hline Maxilla length & 0.94 & 0.12 & 0.49 & -0.41 \\
\hline Nasal length & 0.91 & 0.00 & 0.14 & -0.22 \\
\hline Pterygoid length & 0.91 & 0.04 & 0.30 & -0.11 \\
\hline Presacral Vertebra I length & 0.79 & 0.14 & -0.12 & 0.32 \\
\hline Presacral Vertebra II length & 0.86 & 0.16 & -0.24 & 0.58 \\
\hline Presacral Vertebra III length & 0.88 & 0.15 & -0.25 & 0.62 \\
\hline Presacral Vertebra IV length & 0.89 & 0.15 & -0.24 & 0.65 \\
\hline Presacral Vertebra V length & 0.87 & 0.20 & -0.30 & 0.55 \\
\hline Presacral Vertebra VI length & 0.83 & 0.29 & -0.44 & 0.50 \\
\hline Presacral Vertebra I width & 0.85 & 0.15 & -0.18 & 0.22 \\
\hline Presacral Vertebra II width & 0.94 & 0.11 & -0.18 & -0.04 \\
\hline Presacral Vertebra III width & 0.94 & 0.12 & -0.49 & -0.44 \\
\hline Presacral Vertebra IV width & 0.93 & 0.18 & -0.63 & -0.50 \\
\hline Presacral Vertebra V width & 0.92 & 0.21 & -0.65 & -0.51 \\
\hline Presacral Vertebra VI width & 0.93 & 0.21 & -0.66 & -0.48 \\
\hline Sacrum width & 0.93 & 0.20 & -0.51 & -0.17 \\
\hline Presacral Vertebra II transverse process length & 0.87 & 0.10 & -0.16 & 0.22 \\
\hline Presacral Vertebra III transverse process length & 0.90 & 0.10 & -0.30 & -0.39 \\
\hline Presacral Vertebra IV transverse process length & 0.85 & 0.14 & -0.43 & -0.49 \\
\hline Presacral Vertebra V transverse process length & 0.85 & 0.18 & -0.48 & -0.51 \\
\hline Presacral Vertebra VI transverse process length & 0.86 & 0.18 & -0.50 & -0.49 \\
\hline Sacral diapophysis length & 0.92 & 0.17 & -0.24 & 0.01 \\
\hline Urostyle length & 0.94 & 0.05 & 0.01 & 0.03 \\
\hline Urostyle width & 0.86 & 0.12 & -0.21 & 0.18 \\
\hline Clavicle length & 0.85 & 0.01 & 0.06 & -0.28 \\
\hline Coracoid length & 0.93 & 0.05 & 0.01 & -0.25 \\
\hline Scapula length & 0.84 & 0.12 & -0.03 & 0.08 \\
\hline Scapula width & 0.91 & 0.09 & 0.03 & 0.49 \\
\hline Suprascapula length & 0.94 & 0.10 & 0.09 & 0.16 \\
\hline Pelvic girdle length & 0.97 & 0.09 & 0.42 & 0.25 \\
\hline Iliac crest length & 0.91 & 0.12 & 0.24 & -0.02 \\
\hline Iliac protuberance height & 0.97 & 0.00 & 0.68 & 0.15 \\
\hline Iliac shaft length & 0.95 & 0.11 & 0.33 & 0.09 \\
\hline Supra-acetabular depression height & 0.96 & 0.01 & 0.61 & 0.17 \\
\hline Supra-acetabular expansion height & 0.96 & 0.03 & 0.51 & 0.16 \\
\hline Humerus length & 0.98 & 0.08 & 0.62 & -0.19 \\
\hline Humeral ventral crest length & 0.91 & 0.01 & 0.19 & 0.18 \\
\hline Radius length & 0.96 & 0.17 & 0.65 & -0.34 \\
\hline Ulna length & 0.97 & 0.15 & 0.69 & -0.31 \\
\hline Femur length & 0.98 & 0.17 & 0.72 & -0.40 \\
\hline Tibiofibula length & 0.97 & 0.19 & 0.76 & -0.38 \\
\hline Tibiale-fibulare length & 0.96 & 0.17 & 0.64 & -0.44 \\
\hline
\end{tabular}

likely included a size increase component within the $M$. stelzneri and $M$. tumifrons groups. It is noteworthy also that ranges of size variations are similar between these two clades, with differences of 1.5-2 times (estimated from geometric means) among smaller and larger specimens.

Based on McDiarmid (1971), Graybeal and Cannatella (1995) proposed a set of cranial synapomorphies for the genus: (1) exostosed frontoparietals that diverge anteriorly; (2) lack of the zygomatic ramus of the squamosal; (3) ossified orbitosphenoid cartilage; (4) parasphenoid fused to the base of the skull; and (5) a broadened base of the alary process of the hyoid. Our observations, based on a more inclusive sample, show that these skeletal traits are highly variable within the genus. In addition, comparison with early branching bufonids show that former interpretations of some features of the genus as derived character states may be misleading.

Peloso et al. (2012) discussed the divergence of frontoparietals, stressing on the variation already shown by McDiarmid (1971). In our sample, partially fused frontoparietals that expose a V-shaped fontanelle anteriorly are present in some specimens. However, skull roof configuration is highly variable within and among species, ranging from frontoparietals completely separated to completely fused along the midline. As for exostosis, except for M. setiba and a strongly ossified specimen of M. klappenbachi, frontoparietal sculpturating was not observed in the genus. Within the early diverging bufonids, ornamentations on the 


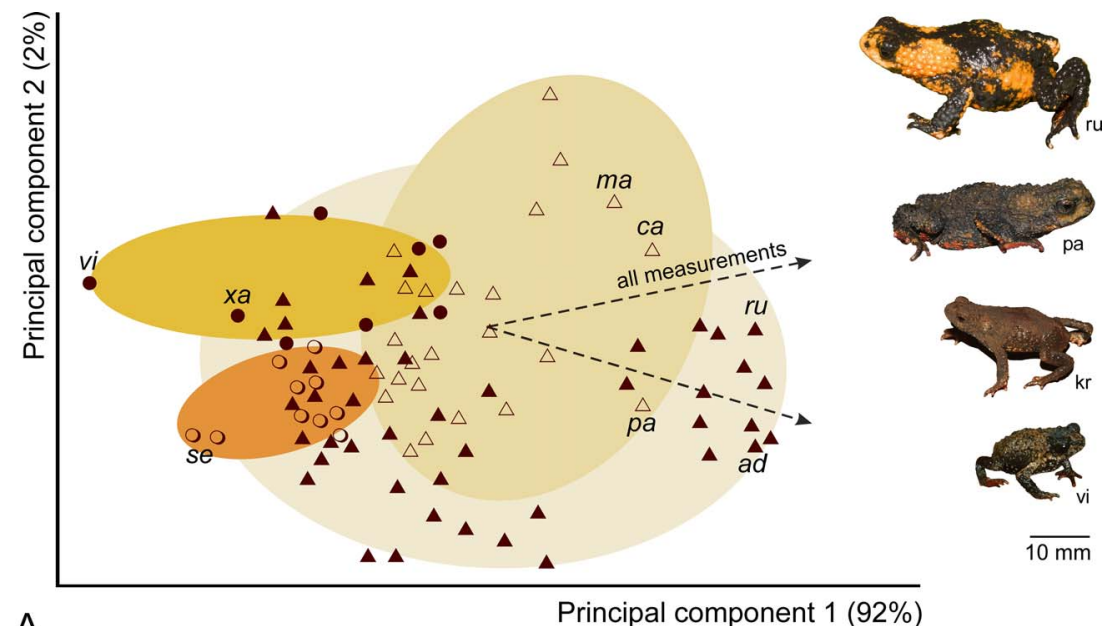

A

Principal component $1(92 \%)$

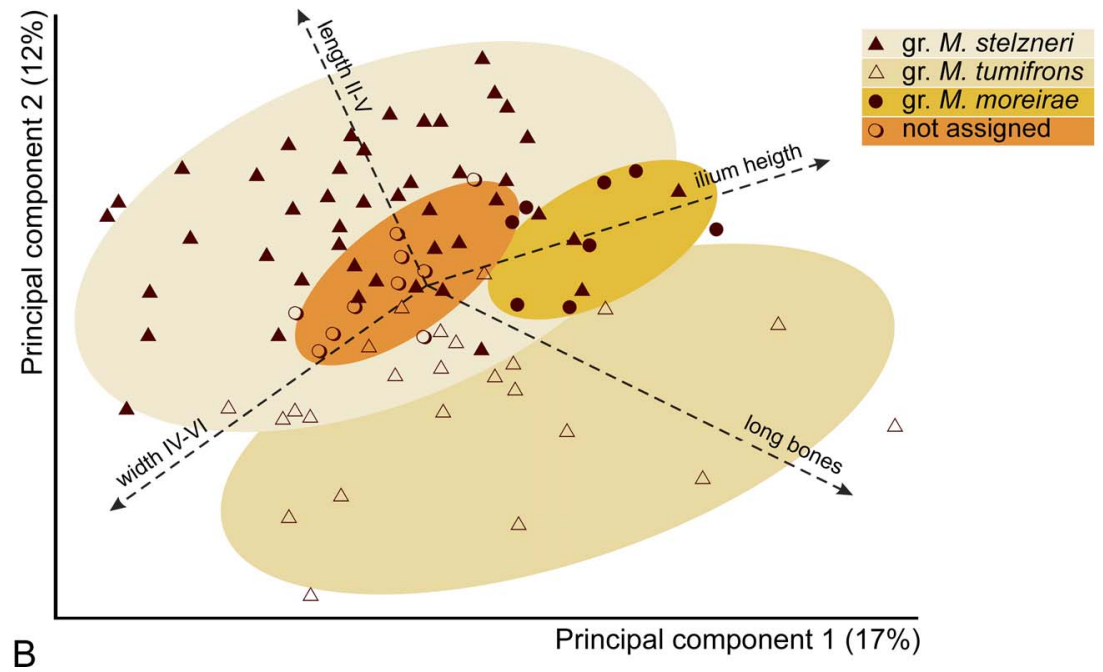

Fig. 19.- Summary of quantitative variations (linear measurements) in cranial and postcranial skeleton of species of Melanophryniscus. Principal component (PC) analyses of (A) raw and (B) size-corrected data showing specimen ordination along components 1 and 2. Symbols represent all specimens analyzed, and ellipses show the approximate distribution of intrageneric groups. Arrows show the original variables as correlated with principal components: all measurements grow highly correlated with raw PC1, whereas size-corrected PC1 and PC2 are mainly explained by length of limb long bones, height of supra-acetabular depression and iliac protuberance (as indicative of ilium body height), width of presacral vertebrae IV-VI, and length of presacral vertebrae II-V. Photographs on the upper right show scaled specimens representative of four groups to highlight the almost threefold difference in body size between smaller and larger species. The smaller and larger species are indicated in the plot: $a d=$ M. admirabilis, ca $=$ M. cambaraensis, ma $=$ M. macrogranulosus, $p a=M$. pachyrhynus, $r u=M$. rubriventris, $s e=M$. setiba, $v i=M$. vilavelhensis, $x a=M$. xanthostomus. Note the wide differences in size among intrageneric groups in (A) and the discrimination of species according to shape in (B). A color version of this figure is available online.

dorsal surface of these bones were only recorded in Osornophryne (Ruiz-Carranza and Hernández-Camacho 1976; Mueses-Cisneros et al. 2010; Páez-Moscoso et al. 2011). In addition, in O. bufoniformis and O. percrassa, frontoparietals also diverge anteriorly, exposing a reduced Vshaped fontanelle (Ruiz-Carranza and Hernández-Camacho 1976). Although a similar opening of the skull roof also occurs in Oreophrynella quelchii, the presence of paired parietal fontanelles makes its cranial architecture different from that of Melanophryniscus species (McDiarmid 1971; Kok et al. 2020). In Atelopus, the frontoparietal fontanelle is closed or almost wholly occluded (Coloma 1997; Coloma et al. 2010), whereas in Frostius these bones are in contact but do not fuse along the midline (Cannatella 1986).

Grant et al. (2006) already noticed a small bump on the squamosal of Melanophryniscus stelzneri and M. estebani (as M. stelzneri) and considered this to be homologous with the zygomatic ramus. In our study, we conclude that squamosals are variable across species in the genus and, although the lack of zygomatic ramus appears to be the general rule, some taxa have bony excrescences likely homologous to the latter in the shape of a spiky projection or a knob-like protuberance. In Atelopus, the zygomatic region of the squamosal is also polymorphic, varying from a well-defined ramus with diverse shapes and orientations (e.g., A. bomolochos, A. carrikeri) to a reduced structure (e.g., A. muisca), sometimes hardly recognizable (e.g., A. ardila, A. boulengeri, A. spumarius; Coloma 1997; Coloma et al. 2010; Hoyos et al. 2015). In Truebella and Osornophryne, although present, the zygomatic ramus is reduced (Ruiz-Carranza and HernándezCamacho 1976; Graybeal and Cannatella 1995; PáezMoscoso et al. 2011).

Regarding the orbitosphenoid, McDiarmid (1971) refers to this structure as the thin layer of cartilaginous tissue that 
surrounds the optic nerve of most anurans and mineralizes or ossifies in Melanophryniscus. According to McDiarmid (1971), the orbitosphenoid integrates with the surrounding endochondral and dermal elements of the skull and may be covered by the posterior extension of the sphenethmoid complex and the anterior projection of the prootics. In contrast, Cannatella (1986) interprets the "orbistosphenoid" as nothing but the expansion of the sphenethmoid and the prootic towards the optic foramen. Disregarding the identity of this structure (i.e., an independent ossified unit or a product of the adjacent bones outgrowing), our observations show that, although in most specimens a bony wall delimits the optic foramen, in some others a nonossified region remains at the skull floor between the optic foramina and beneath the cultriform process of the parasphenoid. Moreover, the ossified orbitosphenoid as proposed by McDiarmid (1971) does not seem exclusive of Melanophryniscus. Although this author described a cartilaginous orbitosphenoid in several species of Atelopus, Dendrophryniscus cf. brevipollicatus (as D. brevipollicatus), and Amazophrynella cf. minuta (as Dendrophryniscus minutus), further studies demonstrated that in some species of Atelopus the lateral region of the optic foramen may calcify partially or totally (Coloma 1997). As one of these species, A. boulengeri, was also included by McDiarmid (1971) as a single specimen, this trait could also be polymorphic. There is no information about the orbitosphenoid cartilage of Truebella and Frostius.

As indicated by McDiarmid (1971), in Melanophryniscus the parasphenoid is integrated with the neurocranium in many of the analyzed specimens; however, in a significant portion, it still can be distinguished from other cranial floor bones. In the other early divergent genera of bufonids, the parasphenoid is not fused with other palatal skull bones except by the posteromedial process in Atelopus farci and A. varius (Coloma 1997), which fuses the ventral surface of the exoccipital. The fusion of the parasphenoid to adjacent elements of the skull seems to be unique to Melanophryniscus.

Finally, the configuration of the hyoid apparatus of Melanophryniscus and the identity of its parts has long been discussed since the first description by Trewavas (1933). Based on observations of hyoid morphology within the genus, and comparisons with other early branching bufonids, the consensus view is that the posterolateral process is absent in Melanophryniscus (e.g., Trewavas 1933; McDiarmid 1971; Baldo et al. 2012b). This appears reinforced by the actual lack of the process in the early branching species $M$. setiba (Peloso et al. 2012). However, after examination of intra- and interspecific variations, which include the presence of distinct posterolateral processes in M. sanmartini and $M$. langonei, we offer an alternative interpretation of hyoid morphology in the genus. From a likely plesiomorphic presence (e.g., it is present in some Atelopus and Truebella; Graybeal and Cannatella 1995; Coloma 1997; Coloma et al. 2010), the posterolateral processes were lost in M. setiba but maintained in the sister clade joining all the remaining species. Antero- and posterolateral processes are conserved as individual structures in $M$. sanmartini + M. langonei but fuse to form a wide cartilaginous sheet in the rest of the genus. Traces of this presumed fusion can be interpreted from an incipient notch in several specimens. A similar scenario was already suggested by Baldo et al. (2012b), who stressed that developmental data would be needed to address this question. In addition, the anteromedial process of the hyalia is considered to be generally absent in the genus, except in M. setiba (Peloso et al. 2012). Our data show that its presence is widespread in the genus because a flat sheet of lightly chondrified cartilage appears on the anterior margin of each hyale, often extending over the entire curved portion. A distinct rod of cartilage, however, does seem to be unique to M. setiba. An anterior process on the hyale is also present in some species of Atelopus (McDiarmid 1971) and Frostius (Cannatella 1986). Other early diverging bufonids have smaller anterolateral processes located in a more anterior position of the hyoid, with the exception of Osornophryne, which lacks both anterolateral and posterolateral processes (Ruiz-Carranza and Hernández-Camacho 1976; Páez-Moscoso et al. 2011).

Other skeletal features of Melanophryniscus deserve further comments. First, the fusion and hyperossification of skull bones were noticed in the earliest descriptions. Jiménez de la Espada (1875) referred to the skull bones joints as "welding" because suture lines are mostly impossible to discern, and McDiarmid (1971) described ornamentation of some dermal bones. As in Melanophryniscus, bones and the underlying cartilaginous scaffold are highly integrated in skull regions of other early diverging bufonids. In Atelopus, the sphenethmoid complex involves at least part of the septum and tectum nasi and reaches the anterior margin of the skull of almost all species; in Amazophrynella and Dendrophryniscus the ossification reaches the posterior part of the vomers (McDiarmid 1971; Coloma 1997; Coloma et al. 2010). In Osornophryne, O. bufoniformis and $O$. percrassa have an ossified sphenethmoid, apparently joined with the solum nasi (Ruiz-Carranza and Hernández-Camacho 1976), while descriptions of $O$. simpsoni refer to a discrete sphenethmoid bone (PáezMoscoso et al. 2011). A fully ossified sphenethmoid complex encompassing the nasal capsules is reported for Frostius pernambusensis (Cannatella 1986). Intra- and interspecific variation of the ossification extent of the sphenethmoid is described in Oreophrynella (Kok et al. 2020). In Truebella, the sphenethmoid is partially fused with the posteriormost part of the septum nasi (Graybeal and Cannatella 1995). In the nasal region, the integration of dermal investing bones with ossified olfactory capsule elements and the sphenethmoid complex was described in several species (e.g., McDiarmid 1971, 1972; Baldo et al. 2012b; Peloso et al. 2012; see also Jiménez de la Espada 1875), and we confirm an almost fully ossified nasal region in all specimens we examined. Exostosis of nasals was only recorded in $M$. setiba and species of the $M$. tumifrons group. In this latter, as pointed out by Baldo et al. (2012b), there is a correlation between this trait and the frontal swelling, a dermal macrogland with a putative defensive role (Naya et al. 2004). Among early branching bufonids, exostosed nasals are only registered in Atelopus carauta (Ruiz-Carranza and Hernández-Camacho 1978). Prootic bones are also evidently sculptured in several species of Melanophryniscus, including representatives of the $M$. stelzneri and $M$. tumifrons groups (e.g., M. klappenbachi and M. devincenzii) and early branching lineages (e.g., M. krauczuki). As already discussed, hyperossification of other skull bones has been reported in 
frontoparietals and occasionally part of the prootics of Osornophryne (Ruiz-Carranza and Hernández-Camacho 1976; Mueses-Cisneros et al. 2010; Páez-Moscoso et al. 2011), in maxillae and squamosals of Oreophrynella seegobini and O. weiassipuensis (and in the nasals of the latter; Kok et al. 2020), and in squamosals and nasals of Atelopus (McDiarmid 1971; Ruiz-Carranza and Hernández-Camacho 1978; Coloma 1997). Ornamentation of ventral skull is not thoroughly described or discussed in these bufonids, but Coloma (1997) briefly commented on the sculptured surface of the sphenethmoid in Atelopus. Our observations in a few specimens of Melanophryniscus of our sample suggest that ventral ornamentation, including the sphenethmoid, prootics, parasphenoid, and exoccipitals, could be highly variable interspecifically and among individuals. Hyperossification, including three variants of ornamentation (exostosis, casquing, and co-ossification; Trueb 1970) has evolved at least 25 times among extant anurans (Paluh et al. 2020). It is known that it involves usually up to five cranial bones (nasals, frontoparietals, premaxillae, maxillae, and squamosals) and, in some groups, also novel elements (prenasals, internasals, and dermal sphenethmoid; Trueb 1970). In Melanophryniscus, besides being intragenerically variable, hyperossification is not as extensive as in other anuran groups (e.g., brachycephalids, ceratophryids, lophyohylini hylids; Fabrezi 2006; Campos et al. 2010; Blotto et al. 2020), as it mainly involves nasals, frontoparietals, and prootics. In their comprehensive study, Paluh et al. (2020) found a wide diversity of skull shapes in hyperossified frogs, as well as strong, although not universal, relationships with feeding on vertebrate preys and displaying phragmotic behavior. These authors do not recover a relation with size. Likewise, hyperossification in Melanophryniscus occurs in the small M. setiba as well as in midsized and large species of M. stelzneri and M. tumifrons groups. Interestingly, none of the small to midsized species of the $M$. moreirae group show bone hyperossification. As in other anuran groups, the ecological implications of hyperossification in Melanophryniscus skull, if any, should be further investigated.

While some authors stated that some species of Melanophryniscus lack palatines (Badenhorst 1945; McDiarmid 1971, 1972; Gluesenkamp 2001), others noted its presence at least as a bone that fuses to underlying structures (Baldo and Basso 2004; Céspedez and Motte 2007; Peloso et al. 2012). Our observations confirm the presence of palatines, even in those species observed by the former authors (M. stelzneri, M. rubriventris, and M. moreirae). These bones are present as discernible elements in all Melanophryniscus species, yet firmly integrated with surrounding structures. Palatines are discernible as discrete bones in Atelopus (McDiarmid 1971; Ruiz-Carranza and Hernández-Camacho 1978; Coloma et al. 2010). Described species of Osornophryne present at least small and slender palatines (Ruiz-Carranza and HernándezCamacho 1976; Páez-Moscoso et al. 2011). In Dendrophryniscus cf. brevipollicatus, palatines are shorter than in Atelopus and fuse to the underlying chondrocranium and nasal processes of the maxillae (McDiarmid 1971). A polymorphic pattern is recorded for Amazophrynella cf. minuta (as D. minutus), where palatines may be either absent or present as small, reduced elements (McDiarmid 1971). Except for the reduction or absence of palatines in Oreophrynella dendronastes and O. macconnelli, species of this genus possess relatively large bones (Kok et al. 2020). Finally, Frostius and Truebella possess palatine bones (Cannatella 1986; Graybeal and Cannatella 1995). Whereas in most early diverging bufonids vomers are recognized as discrete bones (McDiarmid 1971; Cannatella 1986; Kok et al. 2020), in all Melanophryniscus examined they attach firmly to the sphenethmoid complex (e.g., McDiarmid 1971; Baldo and Basso 2004; Céspedez and Motte 2007; Céspedez 2008; Baldo et al. 2012b; Peloso et al. 2012).

The tympanic middle ear, formed of tympanic membrane, middle ear cavity, and columella, is absent in all species of Melanophryniscus. This is a plesiomorphic condition shared with other clades of early diverging bufonids, with independent regains of the complete structure in Frostius and of the tympanic annulus and columella in Atelopus (Pereyra et al. 2016).

Except for those of McDiarmid (1971), detailed descriptions of the axial skeleton of Melanophryniscus are lacking. No qualitative diagnostic features were described in the axial skeleton between species or intrageneric groups, except the dorsal ornamentation of the neural arches plus the aspect of the transversal processes edges (McDiarmid 1971) and the fusion of sacrum and Presacral Vertebra VII in M. setiba (Peloso et al. 2012). The overall appearance of the first four presacral vertebrae is quite conserved throughout the genus. Our observations differ from those of McDiarmid (1971) concerning the aspect of transverse processes, since we do not find scalloped edges in processes of all specimens of $M$. stelzneri and M. rubriventris or smooth edges in processes of all specimens of $M$. moreirae. In addition, the relative size and orientation of the processes of presacral vertebrae $\mathrm{V}-$ VIII regarding the sagittal axis are highly polymorphic. A marked variation in relative size of posterior vertebrae is recovered among intrageneric groups, with species of the $M$. tumifrons group generally having shorter vertebrae with short processes and species of M. moreirae showing narrower posterior vertebrae. Intraspecific variation of shape, size, and orientation of the vertebral processes was also recorded for Atelopus (Coloma 1997; Noriega Noriega 2006). Supernumerary or fused presacral vertebrae are recorded for some specimens of Melanophryniscus in this work, and this was previously noticed by McDiarmid (1971). Abnormalities of the vertebral column are observed as asymmetrical development of the vertebral processes. In particular, the occurrence of a sacral diapophysis in the eight presacral vertebrae of $M$. aff. pachyrhynus is likely similar to a phenomenon described by Coloma (1997) as the unilateral shifting of the sacral diapophysis in five species of Atelopus although, in that case, it results in an ectopic sacral diapophysis attached to one side of the urostyle. While vertebral anomalies are commonly reported in anurans (e.g., Trueb 1977; Púgener and Maglia 2009), diagnostic fusions or changes in number of elements are explored only in some groups. In early branching bufonids, Kok et al. (2020) recovered several independent reductions to seven (Atelopus and Dendrophryniscus), six (Osornophryne), and five (Oreophrynella) presacral vertebrae and found a strong relationship between drastic column shortening and direct development. Interestingly, several small species of bufonid Rhinella with reduction to seven vertebrae are suspected to have some type of endotrophic development (Cusi et al. 2017). Within Melanophryniscus, M. setiba stands as the 
single exception with seven presacral vertebrae. Although the reproductive biology is unknown in this species, observations on female ovarian complement are suggestive of endotrophic development (Peloso et al. 2012). The correlation of vertebra reduction and fusion with other morphological (e.g., digit reduction, small size) or ecological (e.g., developmental mode, locomotion) attributes should be rigorously tested in Bufonidae.

Kaplan (2004) reinterpreted the conditions of pectoral girdle configuration proposed by Noble (1926) by considering fusion and overlap of different regions of epicoracoids as different, variable characters. In this sense, what was defined by McDiarmid (1971) as a dual condition of anteriorly fused (i.e., firmisternal) and posteriorly overlapped (arciferal) epicoracoids is here described as several states of epicoracoid fusion and overlap. The most general pattern in Melanophryniscus combines the anterior fusion of these elements (State A) with different extents of epicoracoid overlap. Further detailed examination, including histological sectioning, would be needed in order to assess states of epicoracoid overlap across the genus. Similarly, the pelvic girdle is highly conservative within the genus. Quantitative variations in proportional height of the ilium body (as indicated by heights of supra-acetabular depression and iliac protuberance) are revealed by size-corrected principal component analysis. The ecological significance of the relatively higher ilium body in species of the $M$. moreirae group relative to early branching species should be further explored.

In the appendicular skeleton, qualitative aspects remain mainly conserved, with the salient exception of the spinelike humeral crest of Melanophryniscus setiba. This was already discussed by Peloso et al. (2012), who stressed on the uniqueness of this feature among bufonids. The morphology of the humerus has undergone considerable changes in some anuran lineages. A large ventral crest has been related to fossorial habits (e.g., Keeffe and Blackburn 2020, and references therein), and humeral spines are suggested to be involved in male combats (e.g., Krohn and Voyles 2014). Although fights for territory and mate choice are frequent in some species of Melanophryniscus (e.g., Baldo 2012), further details on skeletal anatomy and observations on natural history are required to correlate behavior with forelimb configuration in the genus. On the other hand, a wide variation is evident in relative measurements of long bones. Species of the M. stelzneri and M. tumifrons groups show similar ranges of long bone proportions. Interestingly, there appears not to be an allometric pattern in regarding body size, as proportionately shorter or longer bones occur equally in small or large species within each group. In turn, species of the $M$. moreirae group can be distinguished from early branching species by having proportionately longer limb long bones. In the autopodia, the principal differences concern the number, shape, relative size, and extent of calcification of prepollical and prehallical elements. The general condition is that proposed by Fabrezi (1992, 1993, 2001), where the carpus is formed by seven units, including one or two prepollical elements, and the tarsus is formed by seven bones including two prehallical elements. The phalangeal formula in hands and feet are conserved throughout the genus, with the exception of $M$. setiba where this trait is also sexually dimorphic (Peloso et al. 2012).
Lastly, many of the known anuran sesamoids have been already recorded for $M$. pachyrhynus, M. rubriventris. $M$. stelzneri, and M. setiba (Nussbaum 1982; Fabrezi 2006; Baldo et al. 2012b; Peloso et al. 2012; Abdala et al. 2017). Our observations not only extend their presence to other species but also report elements not previously observed for the genus (i.e., pararadial, palmar sesamoid, tibial lunulae, graciella, and fabella). This encourages deeper exploration of these anatomical elements in ad hoc prepared material, since many of the specimens examined were previously disarticulated and their sesamoids probably lost.

In summary, in this study we show that the classical osteological synapomorphies proposed for Melanophryniscus present at least some degree of ambiguity when analyzed not only within the genus but also when compared with the poorly known skull diversity of other early branching bufonids. We emphasize the importance of performing detailed osteological descriptions at more inclusive taxonomic levels for a better understanding of morphological variation and evolutionary trends through groups. Even if some species of Melanophryniscus were included in phylogenetic hypotheses of major taxa (e.g., Pyron and Wiens 2011; Peloso et al. 2012; Pyron 2014; Jetz and Pyron 2018), and partial relationships were proposed (i.e., some Melanophryniscus from phytotelmata; Firkowski et al. 2016; Pie et al. 2017, 2019), we lack an inclusive hypothesis for the intrageneric relationships. The polarity of characters used in our study will depend on the internal relationships of other early diverging bufonids (and consequently on the coding of their osteological characters) and those of Bufonidae with the rest of the Hyloidea, which are still poorly supported or contradictory (Frost et al. 2006; Pyron and Wiens 2011; Pyron 2014; Feng et al. 2017; Hutter et al. 2017; Jetz and Pyron 2018; Streicher et al. 2018). The inclusion of osteological characters in comprehensive phylogenies of Melanophryniscus and Bufonidae, along with the consideration of changes in skeletal development, can yield crucial information about the evolution of the skeleton in toads. Furthermore, diversity in body size has been poorly explored in the genus (but see Bidau et al. 2011). In this context, our work provides supplemental data for further investigation on size evolution and patterns of allometric development of cranial and postcranial skeleton in this amazing group of anurans.

Acknowledgments. - This work was supported by Agencia Nacional de Promoción Científica y Tecnológica (PICT 2018-3349, 2015-2381, and 2015-0813). We thank curators and technical staff of all herpetological collections for the loan of specimens: C.F.B. Haddad and N. Pupin $(\mathrm{CFBH}), \mathrm{M}$. Pie and M. Bornschein (DZUP), E.O. Lavilla, S. Kretzschmar, and M. Canepa (FML), P.J. Torres (LGE), J. Faivovich (MACN), M. Borges Martins and P. Colombo (MCN), S. Castroviejo and G.M. Funk Pontes (MCP), J. Williams and L. Alcalde (MLP A.), and C. Borteiro and F. Kolenc. We thank F. Kolenc and M.V. Segalla for providing us the photos of the adults of Melanophryniscus pachyrhynus and M. vilavelhensis, respectively. We also thank C. García and M. Vera for the valuable assistance provided. Finally, D. Blackburn, M.C. Vallejo-Pareja, and two anonymous reviewers made valuable corrections and suggestions that greatly improved our work.

\section{Supplemental Material}

Supplemental material associated with this article can be found online at https://doi.org/10.1655/HERPMONO GRAPHS-D-20-00002.S1 


\section{Literature Cited}

Abdala, V., M.C. Vera, and M.L. Ponssa. 2017. On the presence of the patella in frogs. The Anatomical Record 300:1747-1755.

Ahl, E. 1938. Über die Kaulquappe des Dendrophryniscus moreirae Miranda-Ribeiro. Zoologischer Anzeiger 124:158-159.

Badenhorst, C.E. 1945. Die Skedelmorfologie van die Neotropiese Anure Atelopus moreirae de Miranda-Ribeiro. Annals of the University of Stellenbosch 23:1-20.

Baldo, D. 2012. Aspectos Taxonómicos, Ecológicos y Genético-Evolutivos en el Género Melanophryniscus Gallardo, 1961 (Amphibia: Anura: Bufonidae). Ph.D. dissertation, Universidad Nacional de Córdoba, Argentina.

Baldo, D., and N.G. Basso. 2004. A new species of Melanophryniscus Gallardo, 1961 (Anura: Bufonidae), with comments on the species of the genus reported for Misiones, Northeastern Argentina. Journal of Herpetology 38:393-403.

Baldo, D., L. Cotichelli, M.O. Pereyra, C. Borteiro, F. Netto, F. Kolenc, F. Brusquetti, and C. Bidau. 2012a. A cytotaxonomic survey of the genus Melanophryniscus Gallardo, 1961 (Anura: Bufonidae). Journal of Herpetology 46:25-33.

Baldo, D., C. Borteiro, F. Kolenc, and S. Rosset. 2012b. The taxonomic status of Melanophryniscus orejasmirandai Prigioni \& Langone, 1987 "1986" (Anura: Bufonidae). Zootaxa 3235:45-61.

Baldo, D., F. Vera Candioti, B. Haad... M.R. Pie. 2014. Comparative morphology of pond, stream and phytotelm-dwelling tadpoles of the South American red-belly toads (Anura: Bufonidae: Melanophryniscus). Biological Journal of the Linnean Society 112:417-441.

Bidau, C.J., D.A. Martí, and D. Baldo. 2011. Inter- and intraspecific geographic variation of body size in South American redbelly toads of the genus Melanophryniscus Gallardo, 1961 (Anura: Bufonidae). Journal of Herpetology 45:66-74.

Blotto, B.L., M.L. Lyra, M.C. Cardoso... A.S. Lantyer-Silva. 2020. The phylogeny of the Casque-headed treefrogs (Hylidae: Hylinae: Lophyohylini). Cladistics 0:1-37.

Bornschein, M.R., C.R. Firkowski, D. Baldo, L.F. Ribeiro, R. BelmonteLopes, L. Corrêa, S.A.A. Morato, and M.R. Pie. 2015. Three new species of phytotelm-breeding Melanophryniscus from the Atlantic Rainforest of southern Brazil (Anura: Bufonidae). PLOS ONE 10:e0142791.

Campos, L.A., H.R. Da Silva, and A. Sebben. 2010. Morphology and development of additional bony elements in the genus Brachycephalus (Anura: Brachycephalidae). Biological Journal of the Linnean Society 99:752-767.

Cannatella, D.C. 1986. A new genus of bufonid (Anura) from South America, and phylogenetic relationships of the Neotropical genera. Herpetologica 42:197-205.

Caramaschi, U., and C.A.G. Cruz. 2002. Taxonomic status of Atelopus pachyrhynus Miranda-Ribeiro, 1920, redescription of Melanophryniscus tumifrons (Boulenger, 1905), and descriptions of two new species of Melanophryniscus from the state of Santa Catarina, Brazil (Amphibia, Anura, Bufonidae). Arquivos do Museu Nacional 60:303-314.

Céspedez, J.A. 2008. Una nueva especie de Melanophryniscus Gallardo, 1961 de Argentina (Amphibia: Anura: Bufonidae). FACENA 24:35-48.

Céspedez, J.A., and M. Motte. 2007. Una nueva especie de Melanophryniscus Gallardo, 1961 de Paraguay (Amphibia: Anura: Bufonidae). FACENA 23:31-42.

Coloma, L.A. 1997. Morphology, Systematics and Phylogenetic Relationships among Frogs of the Genus Atelopus (Anura: Bufonidae). Ph.D. dissertation, University of Kansas, USA.

Coloma, L., W. Duellman, A. Almendáriz, S. Ron, A. Terán-Valdez, and J. Guayasamin. 2010. Five new (extinct?) species of Atelopus (Anura: Bufonidae) from Andean Colombia, Ecuador, and Peru. Zootaxa 2574:154.

Cope, E.D. 1865. Sketch of the primary groups of Batrachia Salientia. Natural History Review 5:97-120.

Cruz, C.A.G., and U. Caramaschi. 2003. Taxonomic status of Melanophryniscus stelzneri dorsalis (Mertens, 1933) and Melanophryniscus stelzneri fulvoguttatus (Mertens, 1937) (Amphibia, Anura, Bufonidae). Boletim do Museu Nacional 500:1-11.

Cusi, J.C., J. Moravec, E. Lehr, and V. Gvoždík. 2017. A new species of semiarboreal toad of the Rhinella festae group (Anura, Bufonidae) from the Cordillera Azul National Park, Peru. ZooKeys 673:21-47.

Daly, J.W., H.M. Garraffo, T.F. Spande, H.Y.C. Yeh, P.M. Peltzer, P.M. Cacivio, J.D. Baldo, and J. Faivovich. 2008. Indolizidine 239Q and quinolizidine 275I. Major alkaloids in two Argentinian bufonid toads (Melanophryniscus). Toxicon 52:858-870.
Darst, C.R., and D.C. Cannatella. 2004. Novel relationships among hyloid frogs inferred from $12 \mathrm{~S}$ and $16 \mathrm{~S}$ mitochondrial DNA sequences. Molecular Phylogenetics and Evolution 31:462-475.

Di-Bernardo, M., R. Maneyro, and H. Grillo. 2006. New species of Melanophryniscus (Anura: Bufonidae) from Rio Grande do Sul, Southern Brazil. Journal of Herpetology 40:261-267.

Duméril, A.M.C., and G. Bibron. 1841. Erpétologie Générale, Volume 8. Roret, France.

Fabrezi, M. 1992. El carpo de los anuros. Alytes 10:1-29.

Fabrezi, M. 1993. The anuran tarsus. Alytes 11:47-63.

Fabrezi, M. 2001. A survey of prepollex and prehallux variation in anuran limbs. Zoological Journal of the Linnean Society 131:227-248.

Fabrezi, M. 2006. Morphological evolution of Ceratophryinae (Anura, Neobatrachia). Journal of Zoological Systematics and Evolutionary Research 44:153-166.

Feng, Y.J., D.C. Blackburn, D. Liang, D.M. Hillis, D.B. Wake, D.C. Cannatella, and P. Zhang. 2017. Phylogenomics reveals rapid, simultaneous diversification of three major clades of Gondwanan frogs at the Cretaceous-Paleogene boundary. Proceedings of the National Academy of Sciences 114:E5864-E5870.

Firkowski, C.R., M.R. Bornschein, L.F. Ribeiro, and M.R. Pie. 2016. Species delimitation, phylogeny and evolutionary demography of codistributed, montane frogs in the southern Brazilian Atlantic Forest. Molecular Phylogenetics and Evolution 100:345-360.

Frost, D.R. 2020. Amphibian Species of the World: An Online Reference, Version 6.0. Available at https://amphibiansoftheworld.amnh.org. Accessed on February 15, 2020. American Museum of Natural History, USA.

Frost, D.R., T. Grant, J. Faivovich... W.C. Wheeler. 2006. The amphibian tree of life. Bulletin of the American Museum of Natural History 297:1291.

Gallardo, J.M. 1961. Nuevo género de Brachycephalidae (Amphibia, Anura). Neotrópica 7:71-72.

Gluesenkamp, A.G. 2001. Developmental Mode and Adult Morphology in Bufonid Frogs: A Comparative Analysis of Correlated Traits. Ph.D. dissertation, University of Texas, USA.

Grant, T., D.R. Frost, J.P. Caldwell, R. Gagliardo, C.F.B. Haddad, P.K.R. Kok, D.B. Means, B.P. Noonan, W.E. Schargel, and W.C. Wheeler. 2006. Phylogenetic systematics of dart-poison frogs and their relatives (Amphibia: Athesphatanura: Dendrobatidae). Bulletin of the American Museum of Natural History 299:1-262.

Graybeal, A. 1997. Phylogenetic relationships of bufonid frogs and tests of alternate macroevolutionary hypotheses characterizing their radiation. Zoological Journal of the Linnean Society 119:297-338.

Graybeal, A., and D.C. Cannatella. 1995. A new taxon of Bufonidae from Peru, with descriptions of two new species and a review of the phylogenetic status of supraspecific bufonid taxa. Herpetologica 51:105-131.

Griffiths, I.V.O.R. 1954. On the nature of the fronto-parietal in Amphibia, Salientia. Proceedings of the Zoological Society of London 123:781-792.

Guayasamin, J.M. 2004. The Eleutherodactylus orcesi species group (Anura: Leptodactylidae): Comparative osteology and comments on its monophyly. Herpetological Monographs 18:142-174.

Günther, A. 1858. Catalogue of Batrachia Salientia in the Collection of the British Museum, Taylor and Francis, UK.

Hoyos, J.M., P. Medina, and P. Schoch. 2015. Osteology of Atelopus muisca (Anura, Bufonidae) from Colombia. Zootaxa 3905:119-130.

Hutter, C.R., S.M. Lambert, and J.J. Wiens. 2017. Rapid diversification and time explain amphibian richness at different scales in the Tropical Andes, Earth's most biodiverse hotspot. The American Naturalist 190:828-843.

Jetz, W., and R.A. Pyron. 2018. The interplay of past diversification and evolutionary isolation with present imperilment across the amphibian tree of life. Nature Ecology \& Evolution 2:850-858.

Jiménez de La Espada, M.J. 1875. Vertebrados del Viaje al Pacífico: Batracios. A.M. Ginesta, Spain.

Kaplan, M. 2004. Evaluation and redefinition of the states of anuran pectoral girdle architecture. Herpetologica 60:84-97.

Keeffe, R., and D.C. Blackburn. 2020. Comparative morphology of the humerus in forward-burrowing frogs. Biological Journal of the Linnean Society 131:291-303.

Kok, P.J.R., M.A.J. Van der Velden, D.B. Means, S. Ratz, I. Josipovic, M. Boone, and R.W. McDiarmid. 2020. Coping with the extremes: Comparative osteology of the tepui-associated toad Oreophrynella and its bearing on the evolution of osteological novelties in the genus. Zoological Journal of the Linnean Society 190:114-139. 
Krohn, A.R., and J. Voyles. 2014. A short note on the use of humeral spines in combat in Espadarana prosoblepon (Anura: Centrolenidae). Alytes 31:83-85.

Langone, J.A., M.V. Segalla, M. Bornschein, and R.O. de Sá. 2008. A new reproductive mode in the genus Melanophryniscus Gallardo, 1961 (Anura: Bufonidae) with description of a new species from the state of Paraná, Brazil. South American Journal of Herpetology 3:1-10.

Larson, P.M., R.O. de Sá, and D. Arrieta. 2003. Chondrocranial, hyobranchial and internal oral morphology in larvae of the basal bufonid genus Melanophryniscus (Amphibia: Anura). Acta Zoologica 84:145-154.

Lynch, J.D. 1971. Evolutionary relationships, osteology, and zoogeography of leptodactyloid frogs. University of Kansas, Museum of Natural History, Miscellaneous Publication 53:1-238.

McDiarmid, R.W. 1971. Comparative morphology and evolution of frogs of the Neotropical genera Atelopus, Dendrophryniscus, Melanophryniscus and Oreophrynella. Bulletin of the Los Angeles County Museum of Natural History 12:1-66.

McDiarmid, R.W. 1972. La posición sistemática de la rana Atelopus rubriventris Vellard. Physis 31:15-21.

Miranda-Ribeiro, A. 1920. Os Brachycephalideos do Museu Paulista (com três espécies novas). Revista do Museu Paulista São Paulo 12:307-316.

Mueses-Cisneros, J.J., M.H. Yanez-Muñoz, and J.M. Guayasamin. 2010 Una nueva especie de sapo del género Osornophryne (Anura: Bufonidae) de las estribaciones amazónicas de los Andes de Ecuador. Papéis Avulsos de Zoologia 50:269-279.

Naya, D., J.A. Langone, and R.O. de Sá. 2004. Características histológicas de la tumefacción frontal de Melanophryniscus (Amphibia: Anura: Bufonidae). Revista Chilena de Historia Natural 77:593-598.

Noble, G.K. 1922. The phylogeny of the Salientia: 1, Osteology and the thigh musculature: Their bearing on classification and phylogeny. Bulletin of the American Museum of Natural History 46:1-88.

Noble, G.K. 1926. The pectoral girdle of the brachycephalid frogs. American Museum Novitates 230:1-14.

Noriega Noriega, P. 2006. Relación de Parentesco entre Cuatro Especies del Género Atelopus (Anura: Bufonidae) de Alta Montaña Colombiana, Basada en Caracteres Osteológicos. Bachelor thesis, Pontificia Universidad Javeriana, Colombia.

Nussbaum, R.A. 1982. Heterotopic bones in the hindlimbs of frogs of the families Pipidae, Ranidae and Sooglossidae. Herpetologica 38:312-320.

Páez-Moscoso, D.J., J.M. Guayasamin, and M. Yánez-Muñoz. 2011. A new species of Andean toad (Bufonidae, Osornophryne) discovered using molecular and morphological data, with a taxonomic key for the genus. ZooKeys 108:73-97.

Paluh, D.J., E.L. Stanley, and D.C. Blackburn. 2020. Evolution of hyperossification expands skull diversity in frogs. Proceedings of the National Academy of Sciences 117:8554-8562.

Peloso, P.L.V., J. Faivovich, T. Grant, J.L. Gasparini, and C.F.B. Haddad. 2012. An extraordinary new species of Melanophryniscus (Anura Bufonidae) from Southeastern Brazil. American Museum Novitates 3762:1-32.

Pereyra, M.O., M.C. Womack, J.S. Barrionuevo... J. Faivovich. 2016. The complex evolutionary history of the tympanic middle ear in frogs and toads (Anura). Scientific Reports 6:34130.

Pie, M.R., P.R. Ströher, R. Belmonte-Lopesa, M.R. Bornschein, L.F. Ribeiro, B.C Faircloth, and J.E. McCormack. 2017. Phylogenetic relationships of diurnal, phytotelm-breeding Melanophryniscus (Anura: Bufonidae) based on mitogenomic data. Gene 628:194-199.

Pie, M.R., M.R. Bornschein, L.F. Ribeiro, B.C. Faircloth, and J.E. McCormack. 2019. Phylogenomic species delimitation in microendemic frogs of the Brazilian Atlantic Forest. Molecular Phylogenetics and Evolution 141:106627.

Ponssa, M.L., J. Goldberg, and V. Abdala. 2010. Sesamoids in anurans: New data, old issues. The Anatomical Record 293:1646-1668.

Pramuk, J.B. 2006. Phylogeny of South American Bufo (Anura: Bufonidae) inferred from combined evidence. Zoological Journal of the Linnean Society 146:407-452.

Pramuk, J.B., T. Robertson, J.W. Sites, Jr., and B.P. Noonan. 2008. Around the world in 10 million years: Biogeography of the nearly cosmopolitan true toads (Anura: Bufonidae). Global Ecology and Biogeography 17:7283.

Prigioni, C.M., and J.A. Langone. 2000. Una nueva especie de Melanophryniscus Gallardo, 1961, de Argentina y Paraguay:(Amphibia, Anura Bufonidae). Comunicaciones Zoológicas del Museo de Historia Natural de Montevideo 195:1-12.

Púgener, L.A., and A.M. Maglia. 2007. Skeletal morphology and develop- ment of the olfactory region of Spea (Anura: Scaphiopodidae). Journal of Anatomy 211:754-768.

Púgener, L.A., and A.M. Maglia. 2009. Skeletal morphogenesis of the vertebral column of the miniature hylid frog Acris crepitans, with comments on anomalies. Journal of Morphology 270:52-69.

Pyron, R.A. 2014. Biogeographic analysis reveals ancient continental vicariance and recent oceanic dispersal in amphibians. Systematic Biology 63:779-797.

Pyron, R.A., and J.J. Wiens. 2011. A large-scale phylogeny of Amphibia with over 2,800 species, and a revised classification of extant frogs, salamanders, and caecilians. Molecular Phylogenetics and Evolution 61:543-583

Roelants, K., D.J. Gower, M. Wilkinson, S.P. Loader, S.D. Biju, K. Guillau, L. Moriau, and F. Bossuyt. 2007. Global patterns of diversification in the history of modern amphibians. Proceedings of the National Academy of Sciences 104:887-892.

Ruiz-Carranza, P.M., and J.I. Hernández-Camacho. 1976. Osornophryne, género nuevo de anfibios bufónidos de Colombia y Ecuador. Caldasia 11:93-148.

Ruiz-Carranza, P.M., and J.I. Hernández-Camacho. 1978. Una nueva especie colombiana de Atelopus (Amphibia: Bufonidae). Caldasia 12:181197.

Sabaj, M.H. 2019. Standard Symbolic Codes for Institutional Resource Collections in Herpetology and Ichthyology: An Online Reference, Version 7.1. Available at http://www.asih.org. Accessed on October 5, 2020. American Society of Ichthyologists and Herpetologists, Washington, DC. American Society of Ichthyologists and Herpetologists, USA.

Soliz, M., M.J. Tulli, and V. Abdala. 2017. Osteological postcranial traits in hylid anurans indicate a morphological continuum between swimming and jumping locomotor modes. Journal of Morphology 278:403-417.

Steinbach-Padilha, G.C. 2008. A new species of Melanophryniscus (Anura, Bufonidae) from the Campos Gerais region of Southern Brazil. Phyllomedusa. Journal of Herpetology 7:99-108.

Streicher, J.W., E.C. Miller, P.C. Guerrero, C. Correa, J.C. Ortiz, A.J. Crawford, M.R. Pie, and J.J. Wiens. 2018. Evaluating methods for phylogenomic analyses, and a new phylogeny for a major frog clade (Hyloidea) based on 2214 loci. Molecular Phylogenetics and Evolution 119:128-143.

Toledo, L.F., I. Sazima, and C.F.B. Haddad. 2011. Behavioural defences of anurans: An overview. Ethology Ecology \& Evolution 23:1-25.

Trewavas, E. 1933. The hyoid and larynx of the Anura. Philosophical Transactions of the Royal Society of London 222:401-527.

Trueb, L. 1970. Evolutionary relationships of casque-headed tree frogs with co-ossified skulls (Family Hylidae). University of Kansas Publications, Museum of Natural History 18:547-716.

Trueb, L. 1973. Bones, frogs and evolution. Pp. 65-132 in Evolutionary Biology of the Anurans: Contemporary Research on Major Problems (J.L. Vial, ed.). The University of Missouri Press, USA.

Trueb, L. 1977. Osteology and anuran systematics: Intrapopulational variation in Hyla lanciformis. Systematic Biology 26:165-184.

Trueb, L. 1993. Patterns of cranial diversity among the Lissamphibia. Pp. 255-343 in Patterns of Structural and Systematic Diversity (J. Hanken and B.K. Hall, eds.). The University of Chicago Press, USA.

Van Bocxlaer, I., S.P. Loader, K. Roelants, S.D. Biju, M. Menegon, and F. Bossuyt. 2010. Gradual adaptation toward a range-expansion phenotype initiated the global radiation of toads. Science 327:679-682.

Vellard, J. 1947. Un nuevo batracio del Norte Argentino. Acta Zoológica Lilloana 4:115-119.

Wassersug, R.J. 1976. A procedure for differential staining of cartilage and bone in whole formalin-fixed vertebrates. Stain Technology 51:131-134.

Accepted on 25 October 2020 Published on 10 June 2021

\section{APPENDIX}

Specimens Examined

Assignation of species to intrageneric groups follows Baldo et al. (2014), and sex and snout-vent length (SVL) are given when available. Specimens marked with $(*)$ were excluded from principal component analyses. For reference, we include also SVL range values from a larger sampling for each species, obtained from indicated literature or DB (personal communication). 
Melanophryniscus moreirae Group

M. alipioi.-DZUP 353, DZUP 355, DZUP 354*, DZUP 295 (20.77 $\mathrm{mm}$ ). Reference SVL $=19.40-25.64 \mathrm{~mm}$ (Langone et al. 2008).

M. moreirae.-MLP A. 1806 (Female, $29.12 \mathrm{~mm}$ ), MLP A. 1805 (Male, $23.57 \mathrm{~mm}$ ), MLP A. 1804 (Male, $24.08 \mathrm{~mm}$ ). Reference SVL = 20.60-29.12 $\mathrm{mm}$ (DB, personal communication).

M. vilavelhensis.-LGE 3690. Reference SVL $=12.80-17.20 \mathrm{~mm}$ (Steinbach-Padilha 2008).

M. xanthostomus.-CFBH 41993 (Male, $18.93 \mathrm{~mm}$ ). Reference SVL = 18.10-21.50 mm (DB, personal communication).

\section{Melanophryniscus stelzneri Group}

M. admirabilis.-LGE 04205 (Female, $38.31 \mathrm{~mm}$ ). Reference SVL= 29.48-40.28 mm (Di-Bernardo et al. 2006).

M. aff. montevidensis.-LGE 22696, LGE 22697 (24.82 mm). Reference $\mathrm{SVL}=23.67-28.13 \mathrm{~mm}$ (DB, personal communication).

M. atroluteus._LGE 09530, LGE 09531 (23.52 mm), LGE 09534, LGE 09536, LGE 09537, LGE 09538, LGE 09539, LGE 09542. Reference SVL $=18.30-29.22 \mathrm{~mm}$ (DB, personal communication).

M. cupreuscapularis.-LGE 19272 (Male, 22.24 mm), LGE 11047 (Male, $25.70 \mathrm{~mm}$ ), LGE 11049 (Male). Reference SVL = 19.47-26.56 mm (DB, personal communication).

M. dorsalis.-LGE 14356, MCP 0235 (Female, 26.75 mm), MCP 0244*. Reference SVL $=18.30-34.35 \mathrm{~mm}$ (DB, personal communication).

M. estebani.-MLP A. 1782 (Male, 30.64 mm), MACN 35405 (Female, $31.86 \mathrm{~mm}$ ). Reference SVL = 25.00-34.00 mm (Céspedez 2008).

M. fulvoguttatus.-LGE 22691 (Male), LGE 19038 (Female). Reference $\mathrm{SVL}=20.01-27.13 \mathrm{~mm}$ (DB, personal communication).

M. klappenbachi.-MLP A. 2268 (Male), LGE 11051, MCP 11956. Reference SVL $=19.80-32.36 \mathrm{~mm}$ (Prigioni and Langone 2000; DB, personal communication).

M. montevidensis.-LGE 11045, MLP A. 1725*, MLP A. 1091 (Male, $22.51 \mathrm{~mm}$ ), MLP A. 1716 (Male, $23.22 \mathrm{~mm}$ ), LGE 22699, LGE 19292 (Male, $21.57 \mathrm{~mm}$ ). Reference SVL $=18.61-31.52 \mathrm{~mm}$ (DB, personal communication).

M. paraguayensis.-LGE 22690 (Male, $23.01 \mathrm{~mm}$ ). Reference SVL = 20.50-25.60 mm (Céspedez and Motte 2007).

M. rubriventris.-LGE 11044 (Male), FML 1520, FML 2502, FML 1484/133, FML 1477 (1), FML 1477 (2), FML 5083 (1)*, FML 5083 (2),
LGE 21219, LGE 21220, LGE 21221, LGE 21222, LGE 22692 (Male, 39.93 $\mathrm{mm}$ ). Reference SVL = 32.05-42.67 mm (DB, personal communication).

M. stelzneri.-LGE 01877, LGE 01885 (24.33 mm), LGE 01886 (24.04 $\mathrm{mm}$ ). Reference SVL $=22.33-32.90 \mathrm{~mm}$ (DB, personal communication).

\section{Melanophryniscus tumifrons Group}

M. aff. devincenzii.-LGE 11054 (Male, 24.94 mm), LGE 11055 (Male, $23.32 \mathrm{~mm}$ ), LGE 11061 (Male, $22.17 \mathrm{~mm}$ ), LGE 11062 (Male, $24.24 \mathrm{~mm}$ ), LGE 11063 (Male, 21.26 mm), LGE 11058*, LGE 11059*, LGE 11048 (Male, $22.99 \mathrm{~mm}$ ), LGE 22695 (Male, $21.19 \mathrm{~mm}$ ). Reference SVL = 20.20 $27.75 \mathrm{~mm}$ (DB, personal communication).

M. aff. pachyrhynus.-MCP 11928, CFBH 27238 (Male, 22.58 mm), LGE 23241 (Male, $24.66 \mathrm{~mm}$ ). Reference SVL = 23.35-35.22 mm (DB, personal communication).

M. cambaraensis.-MCN 13471 (Male, $29.72 \mathrm{~mm}$ ), MCN 13473 (Male, $31.77 \mathrm{~mm}$ ). Reference SVL $=30.90-36.60 \mathrm{~mm}$ (Caramaschi and Cruz 2002).

M. devincenzii.-LGE 11060 (Male, $23.13 \mathrm{~mm}$ ). Reference SVL = 20.97-32.89 mm (DB, personal communication).

M. macrogranulosus.-MCN 13818 (Male, $31.75 \mathrm{~mm}$ ), MCP 08104. Reference SVL = 32.00-37.90 mm (Caramaschi and Cruz 2002).

M. pachyrhynus._LGE 11046 (Male, 30.62 mm), LGE 11056 (Female). Reference SVL $=$ 21.71-35.44 mm (DB, personal communication).

M. simplex: MCN 11057, MCP 09472, MCP 09473. Reference SVL = 24.51-32.06 mm (DB, personal communication).

M. spectabilis.-MCP 11927, LGE 22694 (Male, $23.31 \mathrm{~mm}$ ), MLP A. 1808 (Male), LGE 22700 (Male), MLP A. 1799 (Male). Reference SVL = 26.19-33.06 mm (DB, personal communication).

\section{Not Assigned to Group}

M. krauczuki.-LGE 11050 (Male, 22.31 mm), LGE 11052*, LGE 11053 (Male, $20.49 \mathrm{~mm}$ ), LGE 11057 (Female, 20.31 mm). Reference SVL = $18.00-24.40 \mathrm{~mm}$ (DB, personal communication).

M. langonei.- LGE 22698 (Male), LGE 23242 (Male), LGE 23243 (Male). Reference SVL = 20.05-21.50 mm (DB, personal communication).

M. sanmartini._LGE 22693 (Male, 21.15 mm), LGE 22022 (Male, 20.64 $\mathrm{mm}$ ). Reference SVL $=18.99-24.92 \mathrm{~mm}$ (DB, personal communication).

M. setiba.-CFBH 15735 (Female), CFBH 15745 (Male, $16.00 \mathrm{~mm}$ ). Reference SVL $=13.80-16.10 \mathrm{~mm}$ (Peloso et al. 2012). 